\title{
, \\ STAT3 Enhances Sensitivity of Glioblastoma to Drug-Induced Autophagy-Dependent Cell Death
}

\author{
Janina Remy ${ }^{1,+}{ }^{\dagger}$ Benedikt Linder ${ }^{1,+} \oplus^{\oplus}$, Ulrike Weirauch ${ }^{2}$, Bryan W. Day ${ }^{3}$, Brett W. Stringer ${ }^{4}(\mathbb{D}$, \\ Christel Herold-Mende ${ }^{5}\left(\mathbb{D}\right.$, Achim Aigner ${ }^{2} \mathbb{D}$, Knut Krohn ${ }^{6}$ and Donat Kögel ${ }^{1,7,8, *} \mathbb{C}$
}

1 Neuroscience Center, Experimental Neurosurgery, Department of Neurosurgery, Goethe University Hospital, 60590 Frankfurt am Main, Germany; Janina.Remy@gmx.de (J.R.); linder@med.uni-frankfurt.de (B.L.)

2 Rudolf-Boehm-Institute for Pharmacology and Toxicology, Clinical Pharmacology, University of Leipzig, 04103 Leipzig, Germany; Ulrike.Weirauch@medizin.uni-leipzig.de (U.W.);

Achim.Aigner@medizin.uni-leipzig.de (A.A.)

3 Sid Faithful Brain Cancer Laboratory, QIMR Berghofer, Herston, QLD 4006, Australia; bryan.day@qimrberghofer.edu.au

4 College of Medicine and Public Health, Flinders University, Sturt Rd., Bedford Park, SA 5042, Australia; brett.stringer@flinders.edu.au

5 Division of Experimental Neurosurgery, Department of Neurosurgery, University Hospital Heidelberg, INF400, 69120 Heidelberg, Germany; Christel.Herold-Mende@med.uni-heidelberg.de

6 Core Unit DNA-Technologies, IZKF, Faculty of Medicine, University of Leipzig, 04103 Leipzig, Germany; Knut.Krohn@medizin.uni-leipzig.de

7 German Cancer Consortium DKTK Partner Site Frankfurt/Main, 60590 Frankfurt am Main, Germany

8 German Cancer Research Center DKFZ, 69120 Heidelberg, Germany

* Correspondence: koegel@em.uni-frankfurt.de; Tel.: +49-69-6301-6923

$\dagger$ These authors contributed equally.

check for

updates

Citation: Remy, J.; Linder, B.;

Weirauch, U.; Day, B.W.; Stringer,

B.W.; Herold-Mende, C.; Aigner, A.;

Krohn, K.; Kögel, D. STAT3 Enhances

Sensitivity of Glioblastoma to

Drug-Induced Autophagy-Dependent

Cell Death. Cancers 2022, 14, 339.

https://doi.org/10.3390/cancers

14020339

Academic Editor: Christine Marosi

Received: 16 December 2021

Accepted: 30 December 2021

Published: 11 January 2022

Publisher's Note: MDPI stays neutral with regard to jurisdictional claims in published maps and institutional affiliations.

Copyright: () 2022 by the authors Licensee MDPI, Basel, Switzerland. This article is an open access article distributed under the terms and conditions of the Creative Commons Attribution (CC BY) license (https:// creativecommons.org/licenses/by/ $4.0 /)$.
Simple Summary: Glioblastoma is the most common primary brain cancer in adults. One reason for the development and malignancy of this tumor is the misregulation of certain cellular proteins. The oncoprotein STAT3 that is frequently overactive in glioblastoma cells is associated with more aggressive disease and decreased patient survival. Autophagy is a form of cellular self digestion that normally maintains cell integrity and provides nutrients and basic building blocks required for growth. While glioblastoma is known to be particularly resistant to conventional therapies, recent research has suggested that these tumors are more sensitive to excessive overactivation of autophagy, leading to autophagy-dependent tumor cell death. Here, we show a hitherto unknown role of STAT3 in sensitizing glioblastoma cells to excessive autophagy induced with the repurposed drug pimozide. These findings provide the basis for future research aimed at determining whether STAT3 can serve as a predictor for autophagy-proficient tumors and further support the notion of overactivating autophagy for cancer therapy.

Abstract: Glioblastoma (GBM) is a devastating disease and the most common primary brain malignancy of adults with a median survival barely exceeding one year. Recent findings suggest that the antipsychotic drug pimozide triggers an autophagy-dependent, lysosomal type of cell death in GBM cells with possible implications for GBM therapy. One oncoprotein that is often overactivated in these tumors and associated with a particularly dismal prognosis is Signal Transducer and Activator of Transcription 3 (STAT3). Here, we used isogenic human and murine GBM knockout cell lines, advanced fluorescence microscopy, transcriptomic analysis and FACS-based assessment of cell viability to show that STAT3 has an underappreciated, context-dependent role in drug-induced cell death. Specifically, we demonstrate that depletion of STAT3 significantly enhances cell survival after treatment with Pimozide, suggesting that STAT3 confers a particular vulnerability to GBM. Furthermore, we show that active STAT3 has no major influence on the early steps of the autophagy pathway, but exacerbates drug-induced lysosomal membrane permeabilization (LMP) and release of cathepsins into the cytosol. Collectively, our findings support the concept of exploiting the pro-death functions of autophagy and LMP for GBM therapy and to further determine whether STAT3 can be employed as a treatment predictor for highly apoptosis-resistant, but autophagy-proficient cancers. 
Keywords: STAT3; glioblastoma; pimozide; autophagy; autophagy-dependent cell death; lysosome; lysosomal-dependent cell death

\section{Introduction}

Glioblastoma (GBM; grade IV glioma, WHO) is a primary brain tumor that mainly occurs in adults. GBM-patients have a very dismal prognosis with a median survival of $\sim 15$ months despite aggressive radiochemotherapy after maximally possible surgery [1]. Since GBMs are characterized by their diffuse infiltrative growth, a complete surgical resection is nearly impossible and the tumors quickly recur, often with an even more aggressive growth [2]. Different molecular subtypes of GBM have been described based on the genetic profiles of the tumors. Although their nomenclature is not uniformly used, the general consensus agrees on three GBM subtypes: proneural, classical and mesenchymal [3,4], of which the latter one is the most aggressive. Signal Transducer and Activator of Transcription (STAT3) is a molecular hub-like oncoprotein that is highly overactivated in GBM and associated with the mesenchymal subtype [5,6]. STAT3 is known to regulate multiple hallmarks of cancer such as proliferation, cell survival, angiogenesis and immune evasion (reviewed in $[7,8])$. The activation of STAT3 is mediated by multiple upstream kinases [9] which phosphorylate the protein at two different sites (reviewed in [10], Tyrosine705 (pY705Stat3) and Serine727 (pS727Stat3). Upon activation, STAT3 forms homodimers or heterodimers with other proteins of the STAT-family, translocates into the nucleus and induces pronounced changes in gene expression. Known targets include genes responsible for various hallmarks of cancer like migration/invasion (MMP2, MMP9; [11,12]) or EMT-like features and immune evasion/suppression (e.g., SNAI1; $[13,14])$. Consequently, we and others previously demonstrated that targeting STAT3 by upstream signaling inhibitors of the STAT3 pathway or by genetic depletion decreases glioma cell proliferation and migration in vitro and prolongs overall survival of tumor-bearing mice in vivo [15-21]. Nonetheless, these approaches have so far not resulted in clinical applications, which is in part due to the lack of specific inhibitors of STAT3, which additionally need to be able to cross the blood-brain barrier.

An underappreciated function of STAT3 is its involvement in autophagy and lysosomal function. Recent studies could already show that STAT3 can transcriptionally regulate several genes relevant for autophagy [22-27]. In addition, unphosphorylated, cytoplasmic STAT3 can have direct, transcription-independent effects on the autophagy pathway [28]. Furthermore, upon translocation to the mitochondria STAT3 was found to decrease mitochondrial reactive oxygen species (ROS) that in turn may trigger autophagy [22,29-32]. Notably, STAT3 has also been reported to be important for regulating lysosomal membrane permeabilization (LMP) and lysosome-dependent cell death (LDCD) during post-lactational regression of the mammary gland epithelium [33,34] and in breast cancer cells [35]. Curiously, under these circumstances STAT3 rather promotes cell death, a function that is in stark contrast to its canonical anti-apoptotic pro-survival role.

The lysosomes have been fittingly described as the "suicide bags" of the cells, because of their low $\mathrm{pH}$ and content of acidic hydrolases which are able to degrade macromolecules [36]. Damage to the lysosomal membrane, for example through cationic amphiphilic drugs [37,38], can trigger lysosomal membrane permeabilization (LMP), causing lysosomal rupture and release of its content into the cytosol [39]. The concomitant release of lysosomal cathepsin proteases and hydrolytic enzymes can lead to a specific type of cell death termed lysosome-dependent cell death (LDCD), that depending on the extent of LMP can have necrotic, apoptotic or apoptosis-like features [39]. LDCD has been observed in several pathophysiological conditions such as inflammation, aging, neurodegeneration and cardiovascular disorders [37,39-41]. It has been reported that cancer cells hijack lysosomes to remodel the extracellular matrix in order to increase tissue invasion and metastasis, while at the same time destabilizing them [42]. Accordingly, an increased expression, activity and 
secretion of cathepsins, as well as changes in lysosomal volume, composition and cellular distribution have been observed in different tumors [43]. Based on the findings suggesting both an increased lysosomal activity and concomitant lysosomal destabilization in certain tumors, these organelles might represent a double-edged sword and render cancer cells more prone to lysosome-targeting agents and LDCD via excessive activation of LMP [42]. In our recent work, we could demonstrate that the repurposed drug Pimozide (Pimo) that acts as a functional inhibitor of the lysosomal enzyme acid sphingomyelinase (FIASMA) stimulates autophagy, impairs lipid trafficking/metabolism and destabilizes lysosomes to induce LMP and a unique cell death modality with characteristics of both autophagy-dependent cell death (ADCD) and lysosome-dependent cell death (LDCD) [38,44]. Based on these features, we propose the term autophagy-dependent lysosomal cell death (ADLCD) for this particular mixed type of cellular demise.

Here, we used multiple isogenic Crispr/Cas9-derived knockout and stable shRNAmediated knockdown cell lines to show that depletion of STAT3 has strong rescuing effects on lysosomal stability and this type of cell death, suggesting that STAT3-proficient tumors are particularly vulnerable to this novel therapeutic approach.

\section{Results}

\subsection{Knockout of STAT3 Attenuates Autophagy-Dependent Cell Death}

To analyze the possible role of STAT3 in ADLCD we first tested a panel consisting of 12 human and murine GBM cell lines for their STAT3 expression level and activation state (Supplemental Figure S1A). We observed that STAT3/Stat3 expression varies between the different cell models (Supplemental Figure S1B), but the highest activation (Tyr705phosphorylation; Supplemental Figure S1C) was found in the human GBM cell MZ-54 and the murine GBM cell line Tu9648. MZ-54 have also been previously shown to have a high expression of STAT3 [45].

Hereafter, we generated STAT3-knockouts via Crispr/Cas9. Successful STAT3-knockouts of MZ-54 were validated via western Blot (Figure 1A). We could confirm the expected limiting effects of the STAT3-KO on several hallmarks of cancer, including proliferation (analyzed by MTT assays; Figure 1B), cell migration (analyzed by scratch migration assays; Supplemental Figure S2A,B) and cell invasion (analyzed by sphere invasion assays into matrigel; Supplemental Figure S2C,D). Lastly, we confirmed decreased gene expression of the known STAT3 target genes [17,18,24-26,46,47] Hypoxia Inducible Factor 1 Alpha (HIF1A), Matrix Metalloprotease 1 (MMP1), MMP2, MMP9, Snail Family Transcriptional Repressor 1 (SNAI1, previously known as Snail), BCL2/adenovirus E1B 19 kDa proteininteracting protein 3 (BNIP3) and BNIP3-like (BNIP3L) as well as Solute Carrier Family 2 Member 1 (SLC2A1, also referred to as GLUT1) and SLC2A3 (also referred to as GLUT3), after depletion of STAT3 (Supplemental Figure S2E).

After successfully confirming the biological applicability of these STAT3-KO cells we analyzed whether loss of STAT3 may influence the sensitivity of the cells to pro-death autophagy and LMP by using recently described ADLCD-inducing drugs consisting of (1) a combination treatment of imipramine and ticlopidine (IM + TIC) [48], which served as a positive control throughout the experiments; (2) Pimozide (Pimo) and (3) STF-62247 (STF) $[38,49]$. Accordingly, either treatment led to reduced cell death induction in all three KO-lines, indicating that loss of STAT3 mitigates this cell death response. Similar findings could be obtained using stable, lentiviral depletion of STAT3 using shRNA in MZ-54 human GBM cells (Supplemental Figure S3). Using the murine Tu9648 GBM cell line and its Crispr/Cas9-mediated Stat3-Kos (Figure 1F) we could confirm that Pimo-induced cell death (Figure 1G) was highly reduced compared to Stat3-proficient cells. Lastly, we tested another human GBM cell line, LN-229, which displays lower STAT3-activation compared to MZ-54 and Tu9648 and generated stable lentiviral knockdowns of STAT3 (Figure 1H). Again, we could show that Pimo-induced cell death is enhanced by STAT3 expression (Figure 1I). 
A

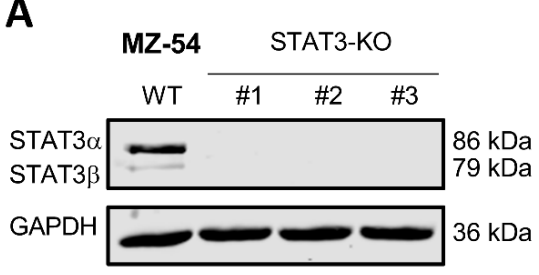

B

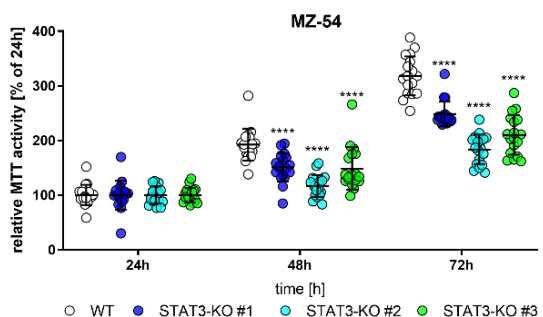

C

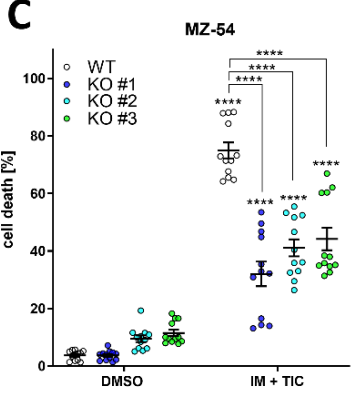

F

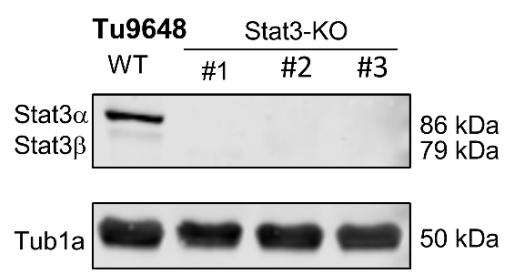

H

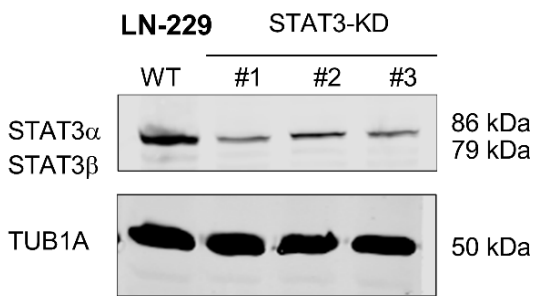

D

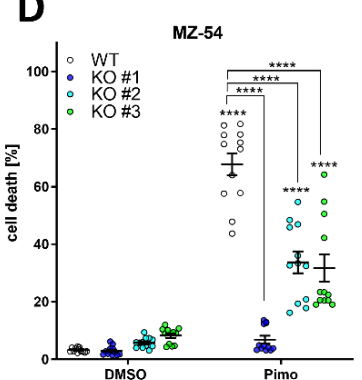

G
E

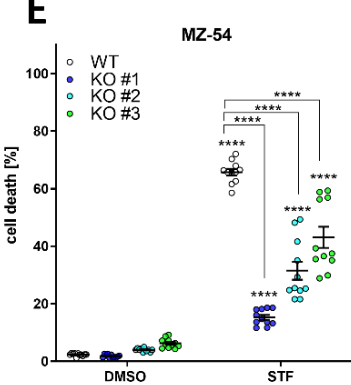

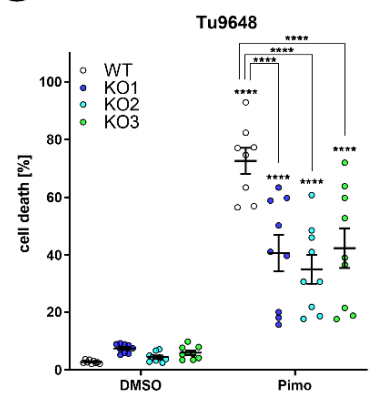

I

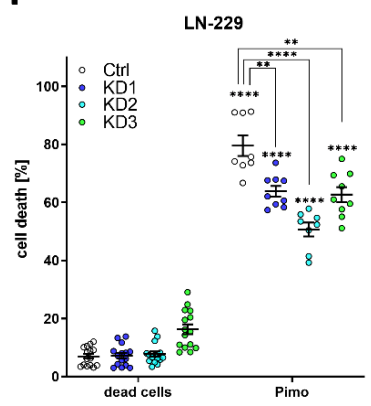

Figure 1. Depletion of STAT3 protects GBM cells from autophagy-dependent cell death. (A) Western Blot of STAT3 after Crispr/Cas9-mediated knockout (KO) of STAT3 in MZ-54 human GBM cells showing complete absence of detectable STAT3 in the KO cell lines. GAPDH served as a housekeeping protein. (B) MTT cell proliferation assay showing reduced growth rate of STAT3-KO cell lines compared to WT. (C-E) ADCD inducers triggered non-apoptotic cell death that could be reversed by complete loss of STAT3. MZ-54 WT and STAT3-KO cells were treated with (C) $20 \mu \mathrm{M}$ imipramine (IM) and $100 \mu \mathrm{M}$ ticlopidine (TIC), (D) $12.5 \mu \mathrm{M}$ pimozide (Pimo) and (E) $40 \mu \mathrm{M}$ STF-62247 (STF) for $40 \mathrm{~h}$. DMSO was used as vehicle control treatment. Total cell death was determined by subsequent Annexin-V-APC/PI staining and FACS analysis. (F) Western Blot of Cripsr/Cas9-mediated KO of Stat3 of the murine GBM cell line Tu9648. (G) Tu9648 WT and Stat3-KO cells were treated with $7.5 \mu \mathrm{M}$ Pimo for $40 \mathrm{~h}$ and cell death was determined. (H) Western Blot of LN-299 human GBM cells after stable depletion of STAT3 using shRNA. (I) LN-229 Ctrl and STAT3-KD cells were treated with $12.5 \mu \mathrm{M}$ Pimo for $40 \mathrm{~h}$ and cell death was determined. The data are presented as point plots of at least three experiments performed with 4 replicates. ${ }^{* *} p<0.01$; ${ }^{* * *} p>0.0001$; Two-Way ANOVA with Tukey's multiple comparison test (GraphPad Prism 9). 
In addition, we re-expressed STAT3 using stable lentiviral overexpression in MZ54 STAT3-KO cells (Supplemental Figure S4A,B) and could show that this leads to a resensitization of Pimo-induced cell death (Supplemental Figure S4C). Lastly, considering that STAT3-activity has been previously associated with the mesenchymal subtype of GBM [5,6] we analyzed if spheroid cultures, so called glioblastoma stem-like cells (GSC), representing the different molecular subtypes show differential sensitivity to Pimo (Supplemental Figure S5). For this purpose, we performed MTT assays of 4 mesenchymal GSCs (FPW1, MN1, RKI1, RN1 [50]), 3 classical GSCs (NCH1425, NCH601 [51], PB1 [50]) and 3 proneural GSCs (NCH644, NCH421k [52], MMK1 [50]) after treatment with 10, 12.5 or $15 \mu \mathrm{M}$ Pimo for 24 or $48 \mathrm{~h}$, respectively. We observed that after $24 \mathrm{~h}$ (Supplemental Figure S5A) the mesenchymal and classical GSC lines show an enhanced sensitivity towards Pimo, since higher concentrations $(>12.5 \mu \mathrm{M})$ were needed to reach statistical significance of MTT activity changes. This is further corroborated after $48 \mathrm{~h}$ (Supplemental Figure S5B) with an effective inhibition in both mesenchymal and classical GSCs using either concentration, whereas proneural GSCs still retain a considerable amount of metabolic activity.

Since changes in ADCD-induction could be caused by a perturbation of the autophagic flux, we next assessed if STAT3-depletion may directly affect it. For this purpose we analyzed the conversion of MAP1LC3B-I (LC3-I) to MAP1LC3B-II (LC3-II) after treatment with Pimo (Figure 2A), STF (Figure 2B,D) and IM + TIC (Figure 2C) and found that in STAT3-WT and STAT3-KO cells all ADLCD-inducing drugs caused a pronounced shift from LC3-I to LC3-II that was independent from the presence of STAT3. We therefore concluded that STAT3 has no major effect on autophagy induction.

To further analyze the functionality of the autophagy pathway, we analyzed the autophagic flux using the LC3-mRFP-GFP tandem construct (ptf-LC3; Addgene \#21074; [53]). Therefore, stable transfectants were generated and analyzed via immunofluorescence after treatment. The autophagic flux can be analyzed because this double-tagged LC3 can be attached to autophagosomes, indicative of autophagy induction, while the EGFP-signal will be quenched after fusion of autophagosomes with lysosomes resulting in mRFP-only positive autolysosomes. By analyzing the ratio of green to red dots, the induction and proceeding of autophagy (i.e., the flux) can be quantified. Accordingly, we observed a pronounced induction of autophagy in both WT and STAT3-KO\#1 (Figure 2D) as well as STAT3-KO\#2 and \#3 (Supplemental Figure S6A,B) cells as shown by multiple doublepositive punctae per cell after treatment with either compound. Additionally, treatment with all drugs was further associated with the presence of red-only punctae, indicating successful fusion of autophagosomes with lysosomes. This was further confirmed after quantifying and calculating the ratio of green and red fluorescence intensity of cells stably transfected with the plasmid pMRX-IP-GFP-LC3-RFP-LC3 $\Delta$ G (Addgene \#84572; [54]) and measurement using a flow cytometer (Figure 2F,G). These experiments showed a decreased EGFP/mRFP-ratio, indicative of an active autophagic flux. Collectively, these experiments led us to conclude that STAT3 has no major influence on the autophagic flux in GBM cells.

\subsection{Knockout of STAT3 Confers Sensitivity to Lysosomal Membrane Permeabilization}

In order to systematically investigate the potential underlying effects of STAT3depletion on drug sensitivity, we took two of the STAT3-KO lines and compared their transcriptomic profiles with control cells under basal, i.e., untreated conditions. We found that in both KO lines, 141 transcripts were significantly decreased and 140 increased compared to WT (Figure 3A,B). Except for STAT3, which was significantly depleted, no other STAT family members were significantly changed. An enrichment analysis (Figure 3C) showed that many lysosomal processes such as lysosome (GO:0005764), primary lysosome (GO:0005766) and lysosomal membrane (GO:0005765) were reduced. Additionally, many processes related to the ER were significantly reduced. The transcriptome analysis further revealed an upregulation of cholesterol transport-mediating Apolipoproteins L (APOLs) (Figure 3D) and a decrease in lipid metabolic processes (Supplemental Figure S7A,B), that have been implicated in cholesterol transport [55] in the absence of STAT3. Recently, we 
showed that the proteomic profiles of MZ-54 cells treated with the ADLCD-inducing drugs Pimo and IM + TIC displayed very similar changes [38], in particular in lipid metabolic processes (most pronounced in cholesterol metabolism) and lysosomal function. In line with the proteomic data, cholesterol accumulation in the lysosomes and perturbed lysosomal function including lysosomal membrane permeabilization (LMP) and ADLCD were observed after treatment with these drugs [38].

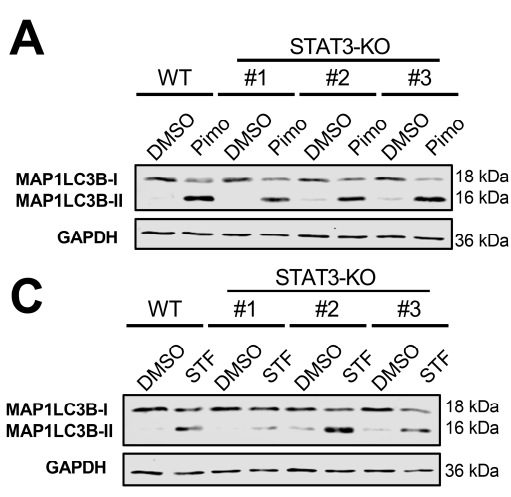

D

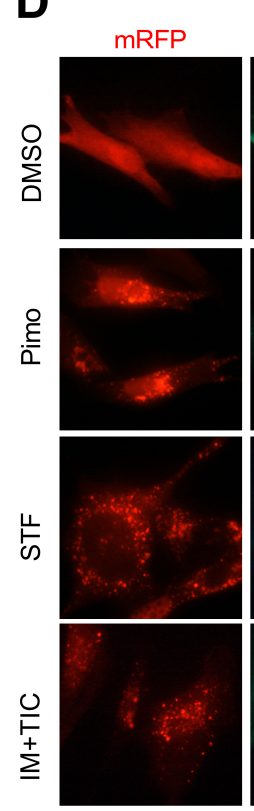

$\mathbf{F}$
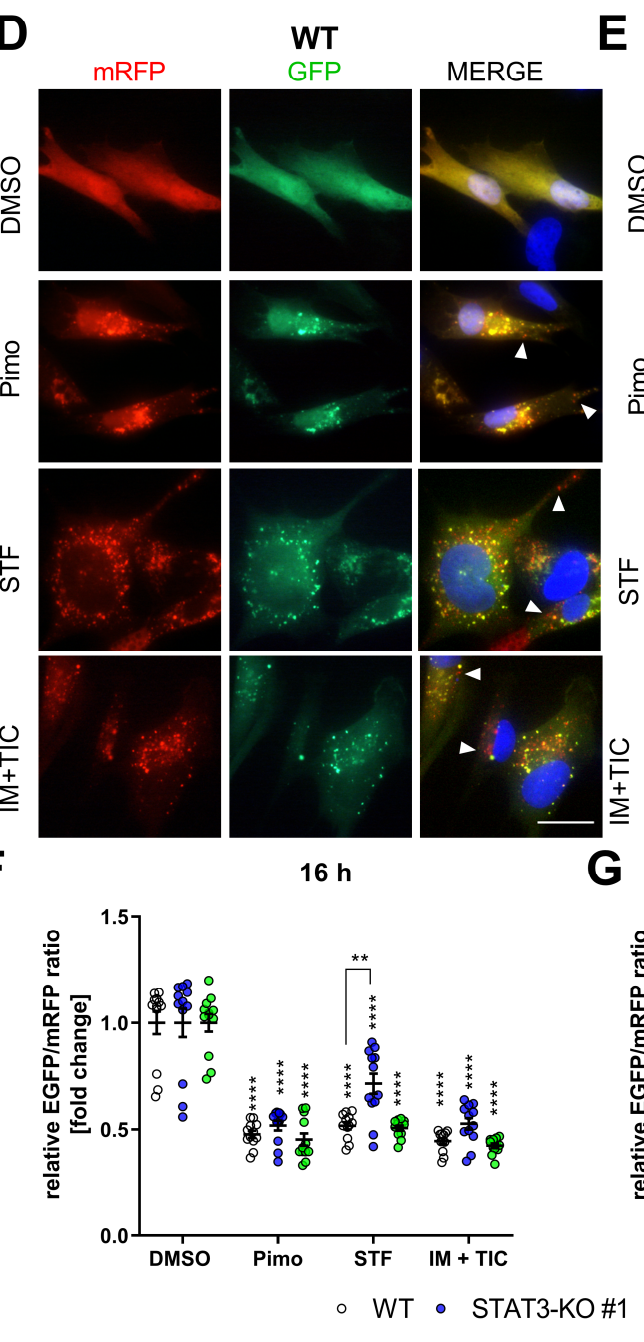

E
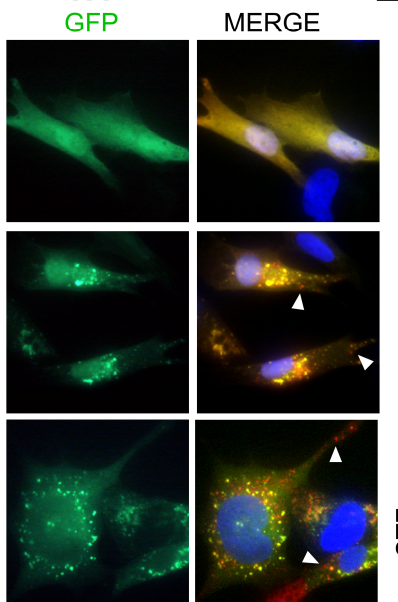

B

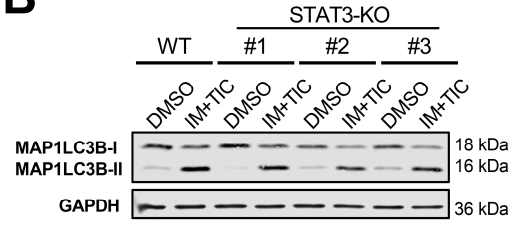

GAPDH $------\longrightarrow 36 \mathrm{kDa}$

$E$
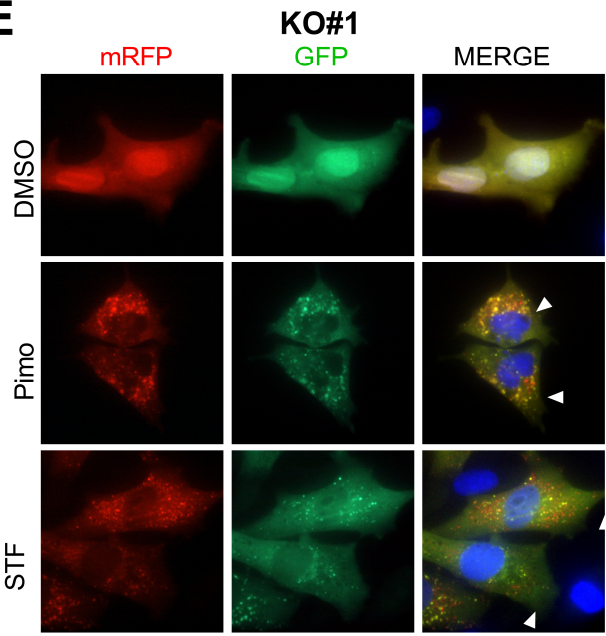
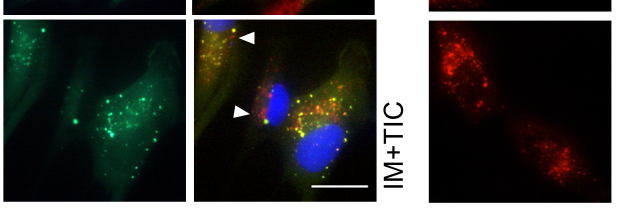

G

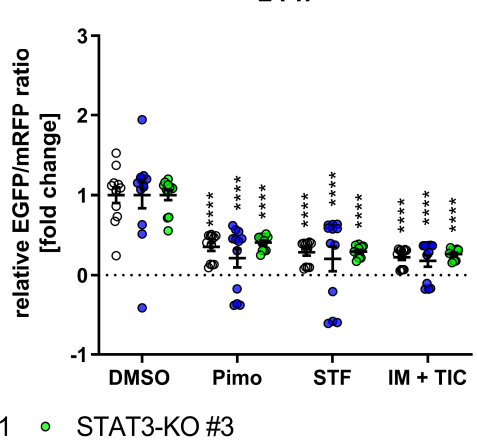

Figure 2. Depletion of STAT3 does not affect autophagy induction or autophagic flux. (A-C) Representative Western Blots of MAP1LC3B-I and II of MZ-54 WT cells and STAT3-KO-cells after treatment with (A) $12.5 \mu \mathrm{M}$ Pimozide (Pimo), (B) $20 \mu \mathrm{M}$ imipramine (IM) and $100 \mu \mathrm{M}$ ticlopidine (TIC) and (C) $40 \mu \mathrm{M} \mathrm{STF-62247} \mathrm{(STF)} \mathrm{for} 6 \mathrm{~h}$. GAPDH served as a housekeeping protein. (D,E) Representative 
pictures of (D) MZ-54 WT cells and (E) STAT3-KO\#1 cells stably transfected with ptf-LC3 for the expression of mRFP-GFP-MAP1LC3B and treated with $15 \mu \mathrm{M}$ Pimo, $40 \mu \mathrm{M}$ STF, $20 \mu \mathrm{M}$ IM and $100 \mu \mathrm{M}$ TIC or vehicle (DMSO) for $24 \mathrm{~h}$. Note that the presence of red-only punctae indicating active flux is unchanged between WT and STAT3-KO cells (arrow heads). Scale bar: $25 \mu \mathrm{m}$. (F,G) Flow cytometric quantification of the autophagic flux using stably transfection of pMRX-IP-GFP-LC3-RFPLC3 $\Delta$ G of MZ-54 WT and STAT3-KO cells. ${ }^{* *} p<0.01 ;{ }^{* * * *} p>0.0001$; Two-Way ANOVA with Tukey's multiple comparison test (GraphPad Prism 7).

A

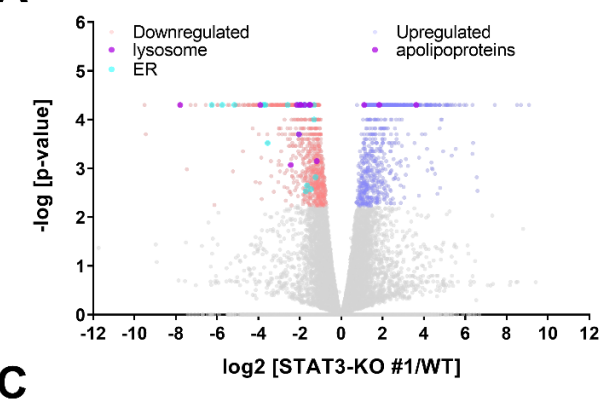

B

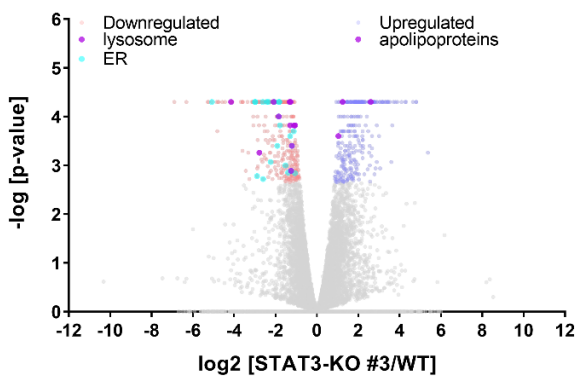

Cellular components DOWN

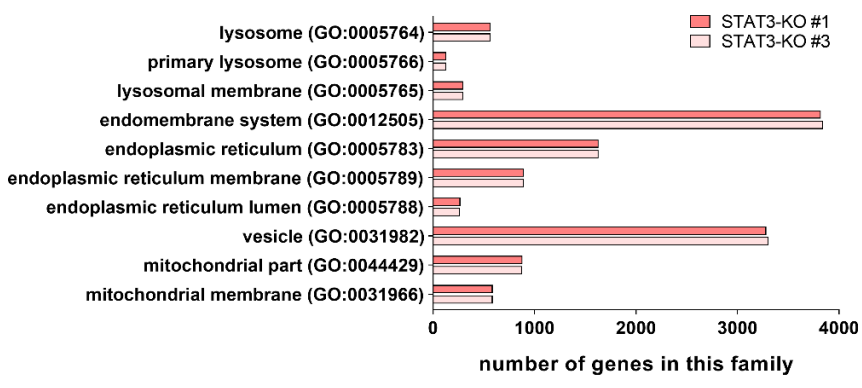

D

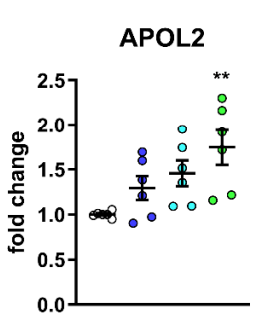

NPRL3

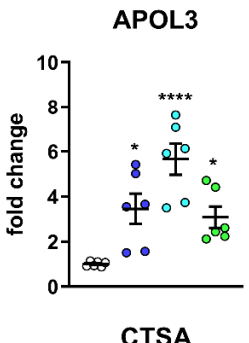

CTSA

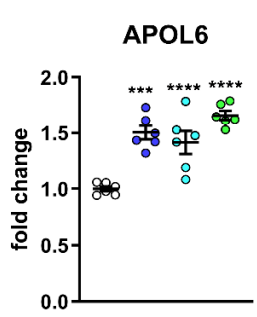

CTSL
BIN1
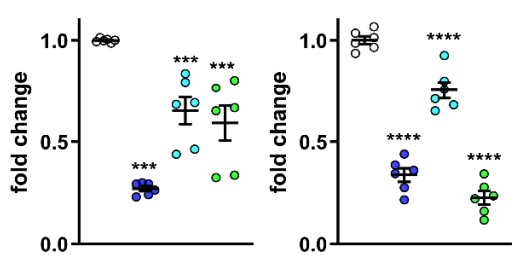

SLC66A1
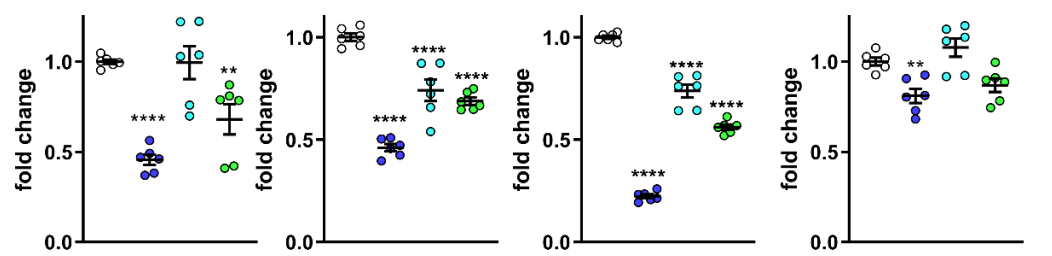

- WT

- STAT3-KO \#1

- STAT3-KO \#2

- STAT3-KO\#3

Figure 3. Transcriptomic analyses after STAT3 depletion in MZ-54-cells reveal changes in lysosomal genes and lipid metabolism and validation of selected target genes. (A,B) Volcano Plots of (A) STAT3KO\#1 vs. WT and (B) STAT3-KO\#3 vs. WT displaying significantly decreased (red) and increased (blue) transcripts. Transcripts related to the lysosome (violet, left side) and ER (cyan, left side) as well as apolipoproteins (violet, right side) are displayed among the significantly regulated transcripts. (C) Bar graphs of selected GO Cellular Component processes after performing an enrichment analysis using PANTHER (Version 14.1, [56]). (D) Point Plots of Taqman-based gene expression analyses of the selected high-ranking candidates APOL2, APOL3, APOL6, BIN1, PLAC8, NPRL3, CTSA, CTSL and PQLC2 from the whole transcriptome analyses of MZ-54 WT cells and STAT3-KO cells. Summary of two experiments performed in triplicates. ${ }^{*} p<0.05$; ${ }^{* *} p<0.01$; ${ }^{* * *} p<0.001$; ${ }^{* * * *} p>0.0001$; One-Way ANOVA with Dunnetts multiple comparison test (GraphPad Prism 7). 
Given that the drugs used in this study have been previously shown to affect lipid metabolic processes and lysosomal function [38,57] and that these processes are also altered in STAT3-KO cells, we validated selected high-ranking candidate genes by qPCR using MZ-54 with STAT3-KO (Figure 3D) and additionally with STAT3-KD (Supplemental Figure S7C). Of those, the three APOL-transcripts APOL2, APOL3 and APOL6, which have been implicated in cholesterol transport [55], were successfully validated. Among the decreased transcripts, we validated (1) BIN1, which is a potential tumor suppressor [58] and is related to the GO-term "endosome to lysosome transport" (GO:000833), (2) PLAC8, that facilitates fusion of autophagosome and lysosomes [59] and (3) NPRL3, which is a lysosomal protein and part of the process "regulation of autophagosome assembly" (GO:2000785). Lastly, we confirmed that the transcripts of the cathepsins A and L (CTSA and CTSL) are decreased in STAT3-depleted cells, whereas the amino acid transporter SLC66A1 can only be considered as moderately reduced in two of the three STAT3-KO clones. Using the GlioVis-portal [60] we correlated STAT3 expression with the expression of these genes derived from TCGA-data [61] across the three different subtypes and without subtyping (Supplementary Figure S8; Supplementary Table S1). We observed that the three APOL-transcripts APOL2, APOL3 and APOL6 (Supplementary Figure S8A-C) are positively correlated with STAT3 across all GBM samples and, except APOL3, also in mesenchymal GBM samples. BIN1, PLAC8 and NPRL3 (Supplementary Figure S8D-F) were not correlated with STAT3 among all GBM, whereas a positive, negative and positive correlation was observed for mesenchymal samples, respectively. CTSA was also positively correlated with STAT3, irrespective of subtype (Supplementary Figure S8G), while CTSL was not included in the dataset. Lastly, SLC66A1 (Supplementary Figure S8H) did not show any correlation with STAT3.

To investigate how lipid trafficking and lysosomal accumulation may be affected by STAT3-depletion we decided to analyze lysosomal cholesterol accumulation as a surrogate for lipid accumulation. For this purpose, we analyzed the cells $18 \mathrm{~h}$ after treatment with IM + TIC, Pimo, STF, solvent (DMSO) or the positive control U18666A (Figure 4), a cationic, amphiphilic drug that inhibits intracellular cholesterol trafficking [62] and staining with the cholesterol-dye Filipin III in combination with the lysosomal marker LAMP1. In MZ-54 WT cells (Figure 4A) we observed a profound colocalization of Filipin III and LAMP1 upon treatment with IM + TIC and Pimo. The three STAT3-KO clones (Figure 4B and Supplemental Figure S9A,B) exhibited decreased colocalization upon treatment with IM + TIC and Pimo, indicating an alleviating effect of the STAT3 KO on lysosomal cholesterol accumulation. Accordingly, the flow cytometric quantification of Lysotracker Deep Red (LTDR; Figure 4C-E) shows that STAT3 depletion also significantly reduced the amount of acidic vacuoles in all three cell lines.

These changes in lysosomal function are in agreement with previous reports showing an involvement of STAT3 in LMP and LDCD [33-35]. To investigate LMP in more detail, we established stable Galectin3 (LGALS3)-mCherry-expressing MZ-54 cells using the pmCherry-Gal3 plasmid (Addgene \#85662; [63]). LGALS3 specifically translocates to leaky membrane of lysosomes $[63,64]$. Upon co-staining with LAMP1 (Figure 5A) as a lysosomal marker several LGALS3-positive punctae were observed after treatment with Pimo in WT cells, which colocalize with LAMP1 [38]. In STAT3-KO cells we can also observe LGALS3-punctae, but to a lesser extent. Upon quantification (Figure 5B), this decrease was found to be statistically significant indicating a reduced rupture of lysosomal membranes in STAT3-KO cells. 
A

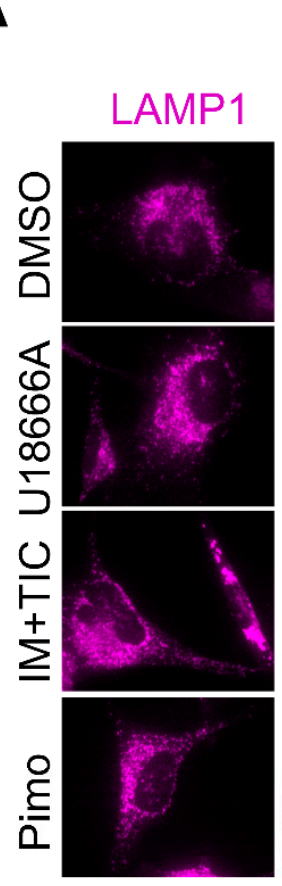

C

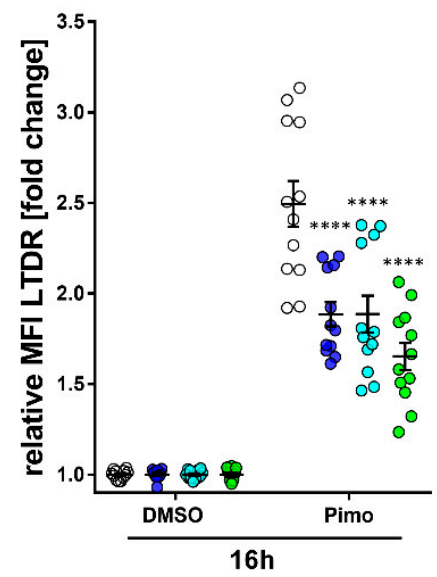

WT
B

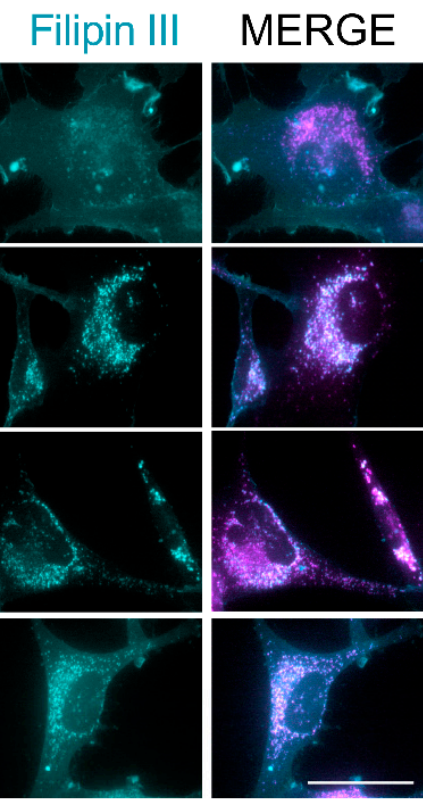

D

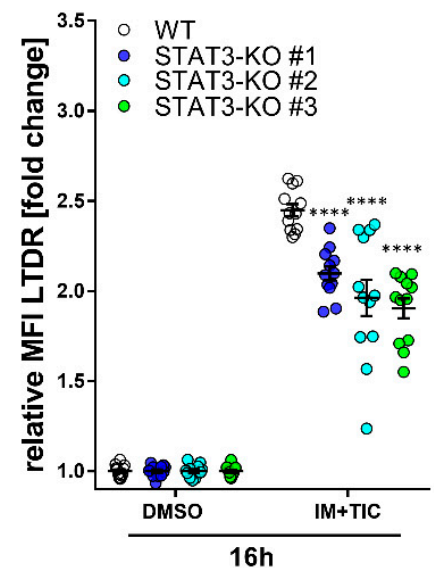

KO\#1

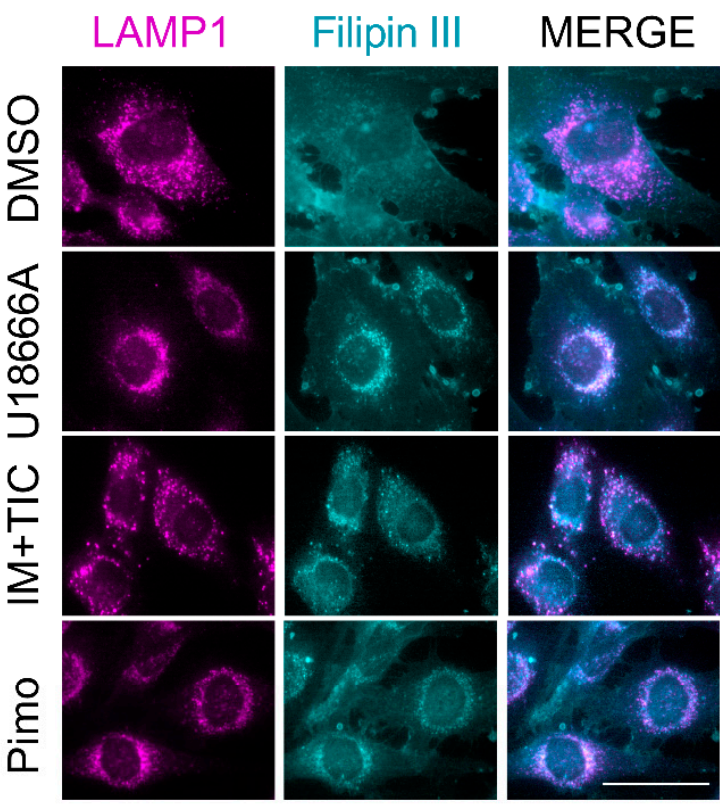

E

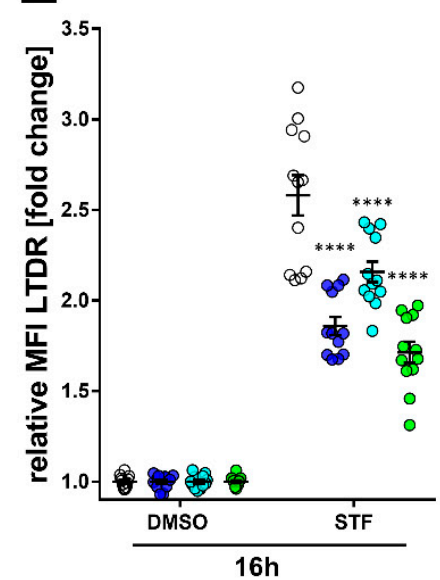

Figure 4. Depletion of STAT3 reduces lysosomal cholesterol accumulation and lysosomal acidification. (A,B) Representative pictures of (A) MZ-54 WT cells and (B) STAT3-KO\#1 cells stained with Filipin III and against LAMP1 after treatment with $15 \mu \mathrm{M}$ Pimozide (Pimo), $40 \mu \mathrm{M}$ STF-62247 (STF), $20 \mu \mathrm{M}$ imipramine (IM) and $100 \mu \mathrm{M}$ ticlopodine (TIC) or vehicle (DMSO) for $18 \mathrm{~h}$. Scale bar: $50 \mu \mathrm{m}$. As a positive control the cells were treated with $1.25 \mu \mathrm{M}$ of the cationic, amphiphile U18666A that inhibits intracellular cholesterol trafficking [62]. Note that white punctae in the merged image indicates cholesterol accumulation within the lysosomes, which is reduced in STAT-KO cells. (C-E) Quantification of lysosomal acidification of MZ-54 WT and STAT3-KO cells using lysotracker deep red after treatment as in $(\mathbf{A}, \mathbf{B})$ for $16 \mathrm{~h}$. The data are presented as point-plots of three experiments performed in 4 replicates. ${ }^{* * *} p<0.0001$; Two-way ANOVA with Sidak's multiple comparison (GraphPad Prism 7). 


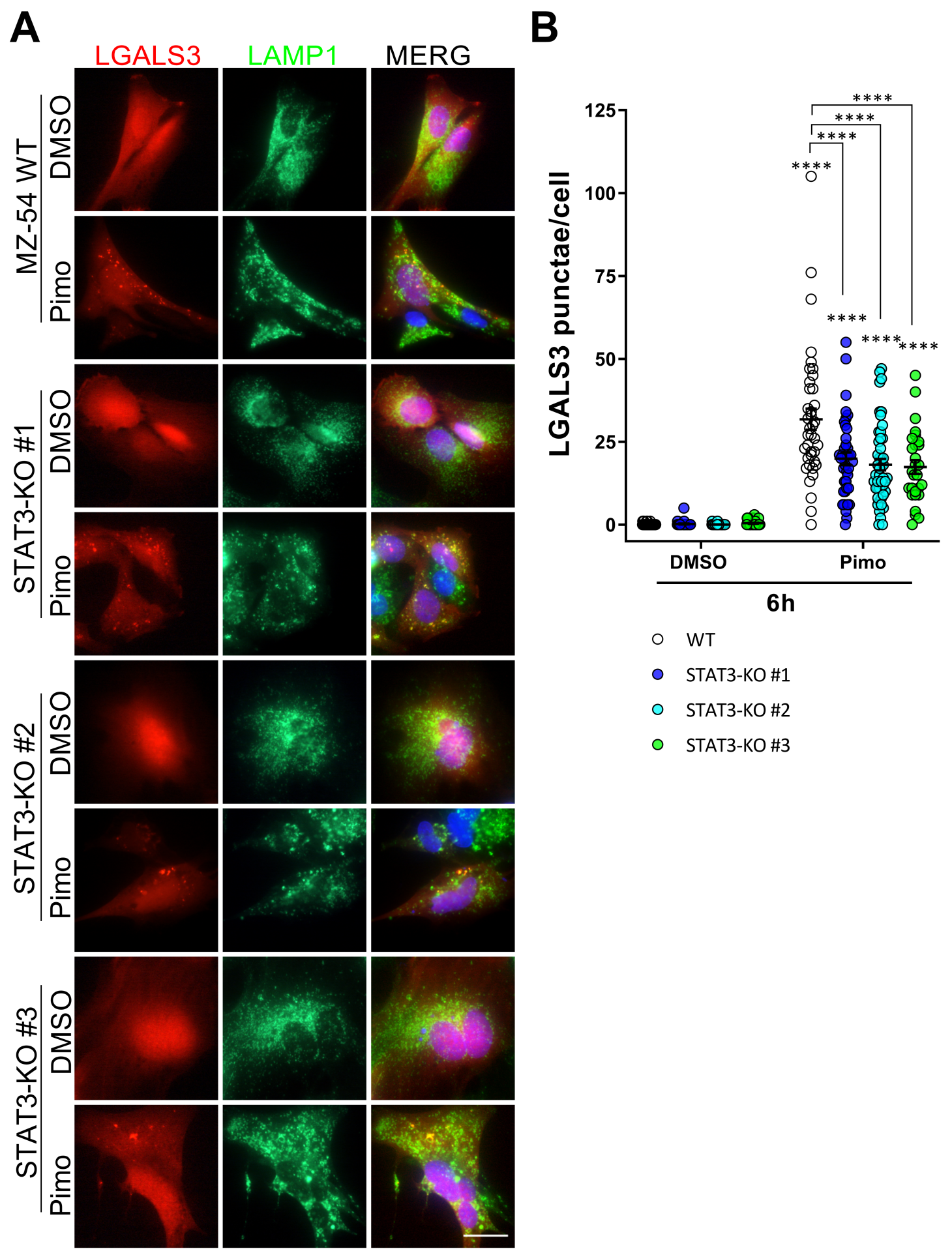

Figure 5. Depletion of STAT3 reduces lysosomal membrane permeabilization and release of lysosomal content. (A) Representative pictures of stably transfected MZ-54 WT and STAT3-KO cells expressing LGALS3-mCherry and co-stained against the lysosomal marker LMAP1 after treatment with $25 \mu \mathrm{M}$ Pimozide (Pimo) or vehicle (DMSO) for $6 \mathrm{~h}$. Note that MZ-54 WT cells exhibit more yellow punctae in the merged view indicating LMP. (B) Quantification of LGALS3-punctae of cells treated as in (A) depicted as point plots of three experiment of which at least 3 vision fields were counted (in total 29 to 48 cells per condition). ${ }^{* * * *} p>0.0001$; Two-Way ANOVA with Tukey's multiple comparison test (GraphPad Prism 7). 
One key characteristic of LMP is the subsequent leakage of lysosomal content, such as cathepsins into the cytosol. Accordingly, we performed digitonin-mediated fractionation of the cytosolic and lysosomal compartments after treatment with IM + TIC, STF or Pimo and detected cathepsin B (CTSB) and D (CTSD) via Western Blot. In WT cells both proteins were found to be prominently enriched in the cytosolic fraction after treatment, whereas the amount of released cathepsins was considerably reduced in at least two out of three knockout lines (Figure 6).

A

$16 \mathrm{~h}$

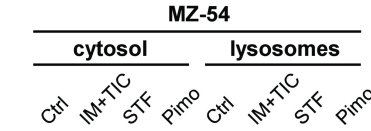

(pre) CTSB

(mature) CTSB

(pre) CTSD

(mature) CTSD

LAMP1

GAPDH

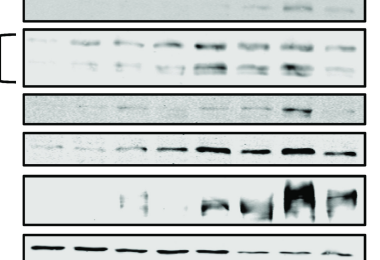

STAT3-KO \#2

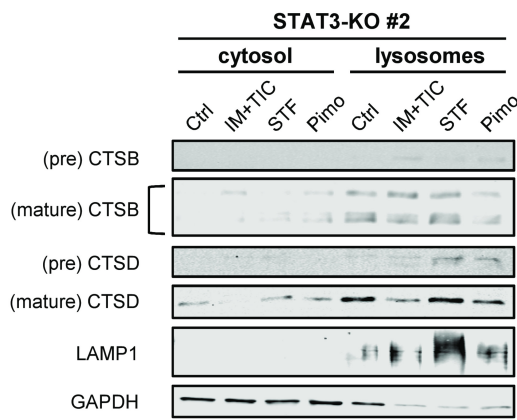

B

CTSB cytosolic

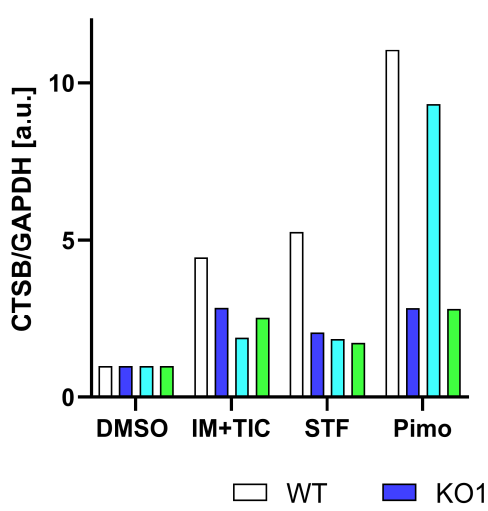

STAT3-KO \#1

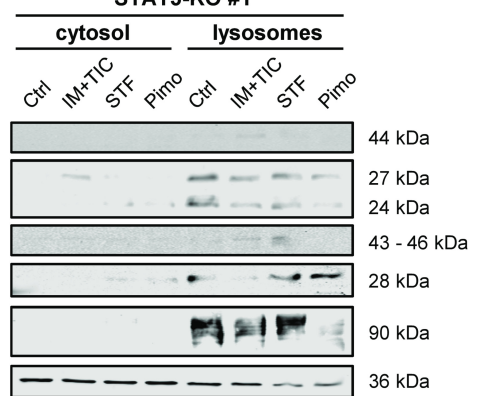

STAT3-KO \#3

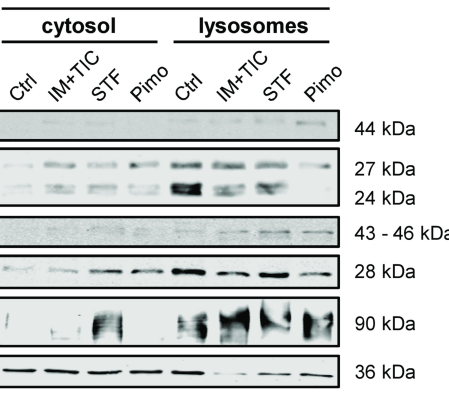

C

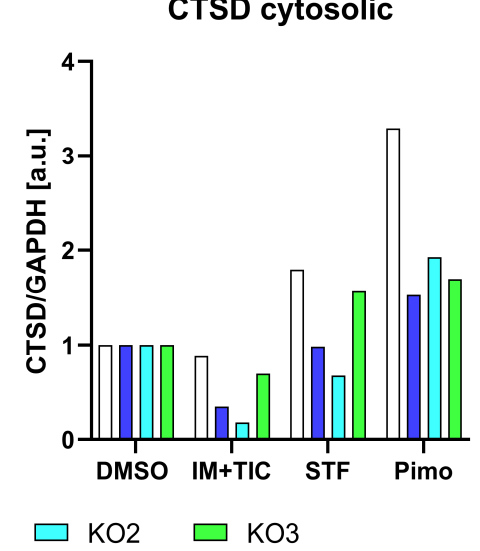

Figure 6. Depletion of STAT3 reduces lysosomal membrane permeabilization and release of lysosomal content. (A) Western Blots of MZ-54 WT and STAT3-KO cells after digitonin-based fractionation of cytosolic and lysosomal proteins $16 \mathrm{~h}$ after treatment with $20 \mu \mathrm{M}$ imipramine (IM) and $100 \mu \mathrm{M}$ ticlopodine (TIC), $15 \mu \mathrm{M}$ Pimozide (Pimo), $40 \mu \mathrm{M}$ STF-62247 (STF) or vehicle (DMSO). LAMP1 and GAPDH served as housekeeping proteins for the lysosomal and cytosolic fraction, respectively. $(\mathbf{B}, \mathbf{C})$ Quantification of the cytosolic fraction of (B) CTSB and (C) CSTD. The data for CTSB and CTSD were first normalized to GAPDH and then to DMSO for each cell line, respectively. 
In order to obtain more quantifiable data, we measured CTSB activity in the cytosolic fraction using a fluorescence-based enzyme kinetic assay (Figure 7). For this experiment, we treated MZ-54 WT and STAT3-KO cells (Figure 7A), as well as MZ-54 shCtrl and STAT3-KD cells (Figure 7B) with Pimo, STF and IM + TIC, and performed digitonin-based fractionation. We found that in WT and shCtrl cells all three treatments evoked significant increases of cytosolic CTSB activity, indicating LMP-induced leakage of lysosomal content into the cytosol. Complete loss of STAT3 (KO) and reduction in STAT3 expression (KD) significantly reduced the extent of cytosolic CTSB activity, sometimes even close to baseline values. Lastly, we reasoned that cathepsin release, which is increased in WT cells, contributes to this cell death modality. Accordingly, pre-treatment with cathepsin inhibitors E64D and pepstatin A prevented Pimo-induced cell death (Figure 7C), in particular in WT cells (Figure 7D), and to a lesser degree in STAT3-KO cells. Although we observed a conclusive trend towards reduced cell death in STAT3-KO cells, we also noticed a basal increase in cell death of the STAT3-KO cells, especially those that seemed to be the least protected from Pimo-induced cell death. Therefore, we calculated the fold change cell death (Figure 7D) for each cell line. Using this approach, we revealed that indeed all STAT3-KO cells are similarly and strongly protected from cell death induction, while the additional cathepsininhibition did not confer an additional survival advantage, likely because of the reduced cathepsin release. We therefore concluded that STAT3-depletion alleviates LMP and ensuing cathepsin-dependent cell death. Similar results could be confirmed in the murine GBM cell model Tu9648, which also display profound inhibition of Pimo-induced cell death in WT cells, upon cathepsin-inhibition (Figure 7E) as well as after calculating the fold change cell death induction (Figure 7F).

A

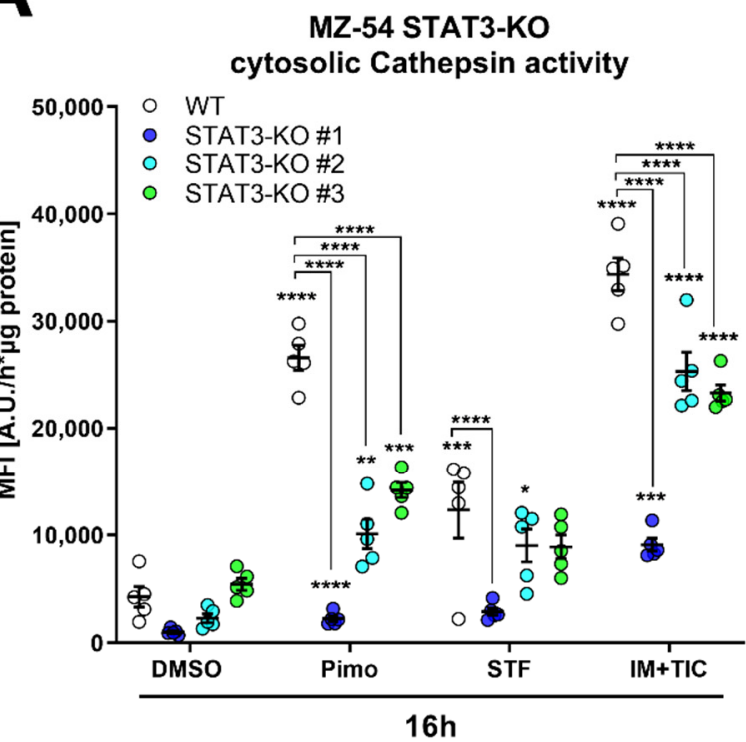

B

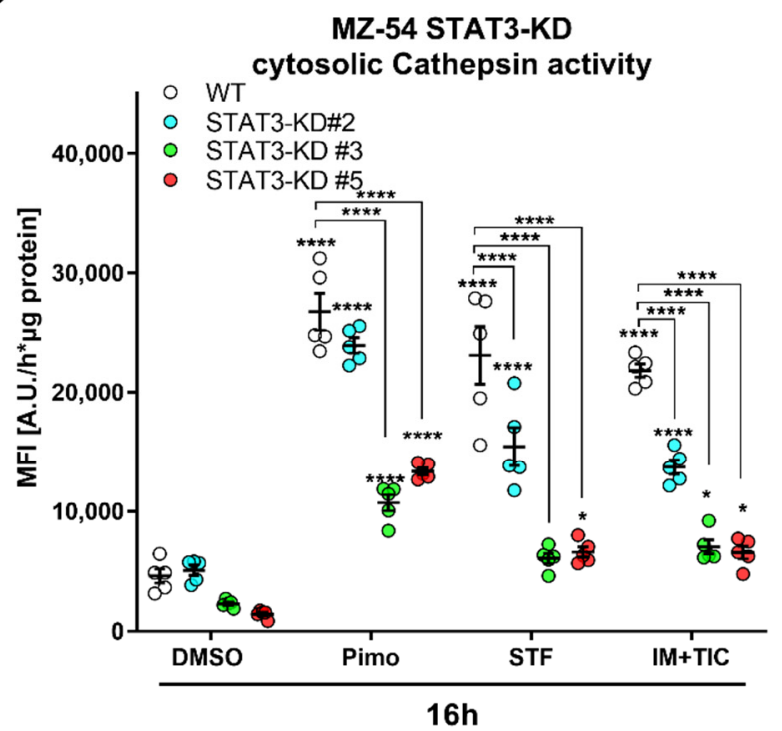

Figure 7. Cont. 
C

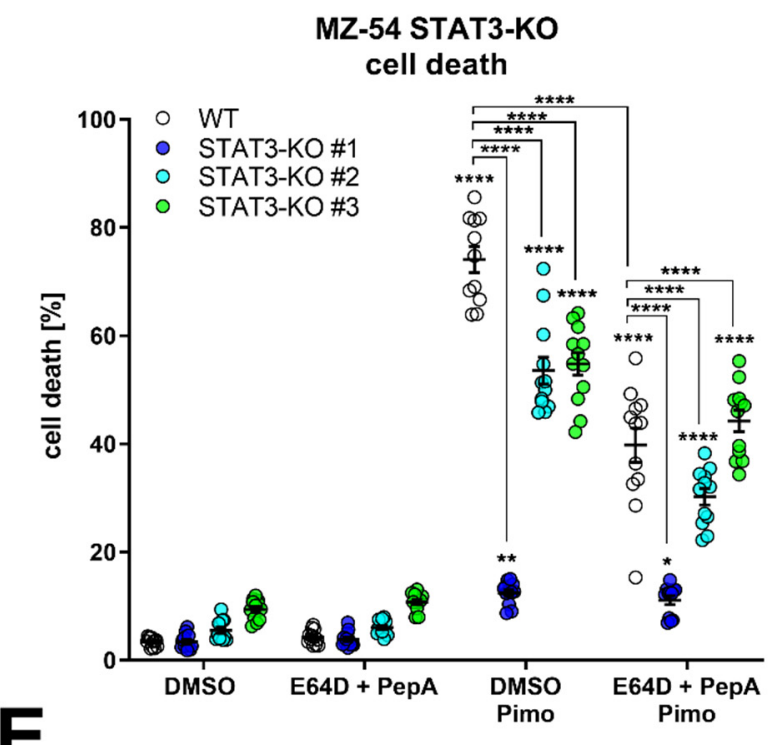

D

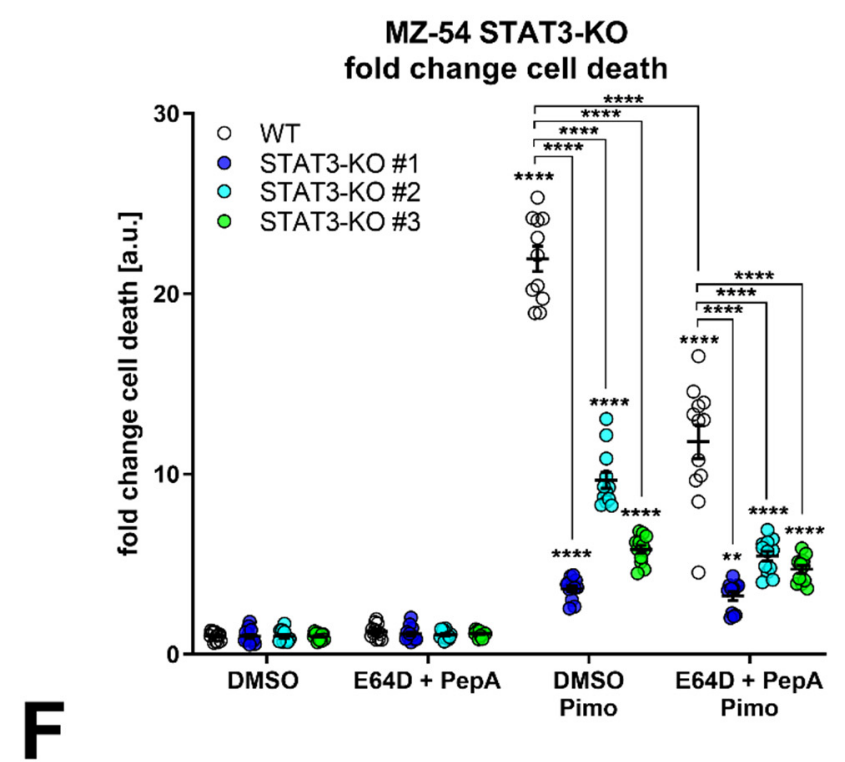

Tu9648 Stat3-KO

fold change cell death

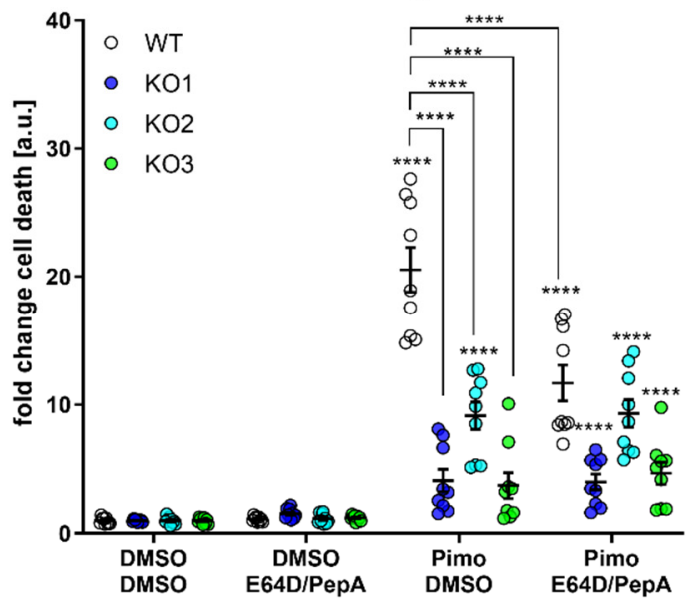

Figure 7. Depletion of STAT3 reduces cytosolic cathepsin activity and inhibition of cathepsins attenuates cell death. (A,B) Cytosolic CTSB activity of (A) MZ-54 WT and STAT3-KO cells and (B) MZ-54 shCtrl and STAT3-KD cells $16 \mathrm{~h}$ after treatment with $20 \mu \mathrm{M}$ imipramine (IM) and $100 \mu \mathrm{M}$ ticlopodine (TIC), $15 \mu \mathrm{M}$ Pimozide (Pimo), $40 \mu \mathrm{M}$ STF-62247 (STF) or vehicle (DMSO) after cytosolic fractionation (for details see materials and methods section). (C) Total cell death was determined by Annexin-V-APC/PI staining and FACS analysis after treatment of MZ-54 WT and STAT3-KO cells after treatment with with $12.5 \mu \mathrm{M}$ Pimozide (Pimo) or vehicle (DMSO) with and without additional treatment with the cathepsin-inhibitors E64D $(25 \mu \mathrm{M})$ and pepstatin A (PepA, $50 \mu \mathrm{M})$. (D) Fold change cell death from the data presented in C. The data are baseline-corrected to each DMSO-treated cell line in order to adjust for baseline cell death-induction after STAT3-KO. (E) Total cell death was determined by FACS analysis of Tu9648 WT and Stat3-KO cells after treatment with 7.5 $\mu$ M Pimo for $40 \mathrm{~h}$ with and without cathepsin-inhibitors. (F) Baseline-correction of the data presented in (E). The data are presented as point plots of $(\mathbf{A}, \mathbf{B}) 2$ experiments performed in 5 replicates and $(\mathbf{C}-\mathbf{F})$ three experiments performed 3-4 replicates. ${ }^{*} p<0.05 ;{ }^{* *} p<0.01 ;{ }^{* * *} p<0.001$; ${ }^{* * *} p>0.0001$; Two-Way ANOVA with Tukey's multiple comparison test (GraphPad Prism 7). 


\section{Discussion}

The oncogenic transcription factor STAT3 acts as a signaling hub molecule involved in regulation of most, if not all hallmarks of cancer, including proliferation, tumor invasion, altered cellular metabolism, angiogenesis, immune evasion and cell survival. Overactivation of STAT3 is frequently observed in malignant gliomas and correlated to the mesenchymal subtype of GBM, a particularly aggressive and treatment-resistant molecular subgroup of these tumors $[9,65,66]$. Therefore, STAT3 represents a very interesting target for GBM therapy. However, STAT3 and other oncogenic transcription factors are a unique class of targets that are very difficult to drug. Therefore, many of the current efforts are focusing on the pharmacological inhibition of upstream JAK kinases in the JAK/Stat pathway, including a phase I clinical trial with the JAK inhibitor WP1066 (NCT01904123), although it should be noted that non-receptor tyrosine kinases such as bone marrow and X-linked (BMX) and members of the Src family can bypass JAK-dependent activation of STAT3 in GBM $[9,67]$. An alternative approach to target STAT3-driven GBMs is to identify and exploit particular vulnerabilities of these tumors. Extensive and prolonged overactivation of autophagy and the concomitant induction of ACD represents a particular sensitivity of GBM cells and an interesting new therapeutic approach $[48,57,68-70]$. While STAT3 has been found to be important for the (positive and negative) regulation of autophagy [32], the exact role of STAT3 in autophagy is highly dependent on the subcellular localization of STAT3 and the cellular context [32].

Recently, we demonstrated that the ACD-inducing compounds Pimo and the combination of IM + TIC, all three being clinically approved drugs that act as "functional inhibitors of the lysosomal enzyme acid sphinogomyelinase" (FIASMAs), severely impair the trafficking/metabolism of cholesterol and other lipids and induce robust lipid-ROS formation to destabilize lysosomal membranes, thereby triggering lysosomal dysfunction and a type of cell death that is dependent both on autophagy and LMP in GBM cells [38]. The current study is a follow-up on this work and we now demonstrate that activated STAT3 significantly increases the sensitivity towards these ACD-inducing drugs, with STAT3-proficient GBM cells showing an increased LMP-mediated leakage of lysosomal content such as cathepsins into the cytosol in comparison to STAT3-depleted cells. This observation suggests that overactivated STAT3 may be useful as a biomarker for ACD susceptibility, a notion that should be investigated in further detail in future studies.

Mechanistically, this death-sensitizing role of STAT3 appears to be independent from alterations in the early steps of the autophagy pathway, because STAT3-deficient and proficient cell lines displayed a very similar extent of LC-3-conversion and an unchanged autophagic flux in our experiments. These findings indicate that STAT3 may rather interfere at the later steps of the autophagosomal/lysosomal pathway, in particular at the lysosomal level. Consistent with this hypothesis, an LMP-promoting role of STAT3 has been documented in several previous studies, for example during mammary gland involution $[33,34]$ as well as in breast cancer cells treated with a derivative of the natural molecule riccardin D [35]. As already outlined above, IM, TIC and Pimo are FIASMAs that accumulate within the lysosomes and induce the detachment and inactivation of acid sphingomyelinase from the lysosomal membrane [71], thereby enhancing deregulation of lipid homeostasis. This event has in turn been correlated to lysosomal stress and LMP [72-74]. Consequently, we did observe partially reduced LMP and release of lysosomal content of STAT3-KO cells following drug treatment compared to WT cells. Of note, lysosomes represent a potential Achilles heel of certain tumors that may be therapeutically exploited. Given the fact that tumor cells often display increased lysosomal activity, but decreased lysosomal stability, lysosomes may represent a particularly suitable target for cancer treatment, because cancer cells may in general be more prone to drug-induced lysosomal destabilization compared to normal tissue [75]. The present study supports the notion that STAT3-driven tumors may be very good candidates for such an approach and our data support the hypothesis that STAT3 has a key role in driving this increased lysosomal activity $[33-35,76]$. This increase may on the one end enhance the metastatic potential of tumors, but at the same time also 
sensitize them for LMP-inducing drugs. Since STAT3 overactivation generally corresponds to a particularly therapy-resistant phenotype, these observations could open new avenues for the treatment of this subgroup of tumors.

In addition to enhanced lysosomal activation, the demand for cholesterol may be a second vulnerability of (STAT3-driven) tumors, in particular GBMs that are incapable of de novo cholesterol synthesis and rely on exogenous cholesterol [77-79]. Hence, the combined targeting of cholesterol trafficking and lysosomal function, as demonstrated to occur with the drugs used in this study [38], appears to be an interesting strategy for the treatment of GBM. Our transcriptome analysis of STAT3-KO versus wild type cells revealed global effects on components of the endomembrane system (including ER) and genes putatively related to cholesterol transport (APOL family members), hinting at the possibility that in addition to facilitating LMP, STAT3-mediated effects on lipid metabolism and trafficking may contribute to drug sensitization.

In conclusion, our data support the concept of using FIASMAs to simultaneously overactivate autophagy and induce LMP in order to target two potential Achilles heels of GBM, i.e., lysosomal function and lipid trafficking as a novel strategy for the treatment of GBM. In light of the sensitizing function of STAT3 in this context, STAT3-driven tumors may be especially suited for such a therapeutic approach.

\section{Materials and Methods}

\subsection{Cells and Cell Culture}

Human GBM cell lines A172 (ATCC \#1620), MZ-18 [80], MZ-54 [80], MZ-256 [80], MZ304 [80], U87-MG (ATCC \#HTB-14), U251-MG (RRID:CVCL_0021), U343-MG (RRID:CVCL_S471), U373-MG ATCC (RRID:CVCL_2219), LN229 (ATCC \# CRL-2611) and the murine GBM lines Tu2449 and Tu-9648 [81] as well as HEK293T cells (ATCC \#CRL-3216) were cultured in Dulbecco's modified Eagle's medium (DMEM GlutaMAX) supplied with heat-inactivated 10\% FBS and $100 \mathrm{U} / \mathrm{mL}$ Penicillin $100 \mu \mathrm{g} / \mathrm{mL}$ Streptomycin (all from Gibco, Darmstadt, Germany) in a humidified incubator at $37^{\circ} \mathrm{C}$ and $5 \% \mathrm{CO}_{2}$. For passaging and seeding, the cells were detached using Trypsin/EDTA-solution (Gibco). The GSC lines PB1, FPW1, MN1, RKI1, RN1, MMK1 were gifted from Bryan Day and Brett Stringer [50] and the GSC lines NCH1425, NCH601 [51], NCH644, NCH421k [52] were gifted from Christel Herold-Mende. All GSCs were cultured in either DMEM/F12 or Neurobasal-A Medium supplied with Glutamax $(1 \times)$, B27 Supplement $(1 \times), 100 \mathrm{U} / \mathrm{mL}$ Penicillin $100 \mu \mathrm{g} / \mathrm{mL}$ Streptomycin (all from Gibco), $20 \mathrm{ng} / \mathrm{mL}$ Epidermal Growth Factor (Peprotech, Hamburg, Germany) and $20 \mathrm{ng} / \mathrm{mL}$ Fibroblast Growth Factor (Peprotech) in suspension flasks.

To generate Crispr/Cas9-knockouts various potential small guide RNAs (sgRNA) were determined using the Web-App Benchling.com and were cloned into pSpCas9(BB)-2APuro (px459) vector (addgene \#48139) as described [82,83]. After validation of successful insertion into the plasmids the cells were transfected with a combination of two different sgRNA-containing plasmids using Lipofectamine 3000 per the manufacturers' instructions. Then, $48 \mathrm{~h}$ after transfection the cells were selected with $1 \mu \mathrm{g} / \mathrm{mL}$ puromycin (Santa Cruz Biotechnology, Dallas, TX, USA)-containing medium for $24 \mathrm{~h}$. Hereafter, the cells were seeded as single cells into 96-well-plates in order to generate isogenic cell lines. Cell lines were thereafter tested for bi-allelic deletion via genotyping PCR and the loss of proteinexpression was verified using SDS-PAGE and Western Blot.

The following sequences were used to generate STAT3-KOs: sgSTAT3_A_sense: 3'aaacCAGTGGCTGCAGTCTGTAGAC-5' , sgSTAT3_A_antisense: 3'-CACCGTCTACAGACT GCAGCCACTG-5'; sgSTAT3_B_sense: 3'-aaacTTGGCTTCTCAAGATACCTGC-5', sgSTAT3 _B_antisense: $3^{\prime}$-CACCGCAGGTATCTTGAGAAGCCAA-5'; sgSTAT3_C_sense: $3^{\prime}$-aaacGT GGGAAGAATCACGCCTTC-5' ', sgSTAT3_C_antisense: $3^{\prime}$-CACCGAAGGCGTGATTCTTC CCAC-5'. MZ-54 STAT3-KO\#1,\#2 and \#3 were generated after transfection of sgSTAT3_A and $B ; A$ and $C ; B$ and $C$, respectively.

Genotyping PCR of STAT3 was conducted using the following Primer: STAT3_fwd: 3'-GTAACGACCTCCCCTTCGC-5', STAT3_rev: 3'-TGTTTTGTCTCAGGTCTCACCT-5'. 
The following sequences were used to generate Stat3-KOs: sgStat3_A_sense: 3'aaacGGCACCTTGGATTGAGAGTC-5' , sgStat3_A_antisense: $3^{\prime}$-CACCGACTCTCAATCC AAGGTGCC-5' ; sgStat3_B_sense: $3^{\prime}$-aaacGCTGTACAGCGACAGCTTCC-5' ${ }^{\prime}$ sgStat3_B _antisense: $3^{\prime}$-CACCGGAAGCTGTCGCTGTACAGC-5' ; sgStat3_C_sense: $3^{\prime}$-aaacCATGGA GCTGCGGCAGTTCC-5' , sgStat3_C_antisense: $3^{\prime}$-CACCGGAACTGCCGCAGCTCCATG5'; sgStat3_D_sense: 3'-aaacGCTGCAGCAGCTGGACACAC-5', sgStat3_D_antisense: $3^{\prime}$ CACCGTGTGTCCAGCTGCTGCAGC-5'

Tu9648 Stat3-KO\#1, \#2 and \#3 were generated after transfection of sgStat3_A and B; B and D; C and D, respectively. Genotyping PCR of Stat3 was conducted using the following Primer: Stat3_Fwd01: 3'-GAAGCCACGTGTGTGGTAGA-5', Stat3_Rev02: 3' TCCTTTTCAGAGTCACCAGGG-5'. All oligonucleotides were ordered from Eurofins Scientific (Eurofins Scientific, Luxembourg, Luxembourg).

To generate stable shRNA-mediated STAT3-KD cells (pLKO.1-puro_shSTAT3; MISSION ${ }^{\circledR}$ SHCLNV-NM_003150, Sigma-Aldrich, Taufkirchen, Germany) or control cells expressing non-mammalian targeting control shRNA (pLKO.1-Puro_shCtrl; MISSION ${ }^{\circledR}$ SHC002, Sigma-Aldrich) 150,000 HEK293T cells were seeded into 6-well plates. After overnight incubation, cells were transfected with $2 \mu \mathrm{g}$ plasmid DNA (pLKO.1-puro), $1.5 \mu \mathrm{g}$ gag/pol plasmid (psPAX2, addgene \#12260) and $0.5 \mu \mathrm{g}$ VSV-G envelope plasmid (pMD2.G, addgene \#12259) in $57 \mu \mathrm{L}$ Opti-MEM and $6 \mu \mathrm{L}$ FuGENE HD (Promega, Fitchburg, WI, USA) transfection reagent. After medium change after $6 \mathrm{~h}$ the viral supernatant was collected after an additional $16 \mathrm{~h}$ and $40 \mathrm{~h}$, pooled, filtered through a $0.45 \mu \mathrm{m}$ filter. The viral supernatant was dilutet 1:1 with fresh medium and supplied $3 \mu \mathrm{g} / \mathrm{mL}$ hexadimethrine bromide (polybrene; Sigma-Aldrich). Puromycin was applied at $5 \mu \mathrm{g} / \mathrm{mL}$ and maintained to select for positively transduced cells. psPAX2 was a gift from Didier Trono (Addgene plasmid \#12260; http:/ / n2t.net/addgene:12260; RRID:Addgene_12260, accessed on: 10 December 2021). pMD2.G was a gift from Didier Trono (Addgene plasmid \#12259; http:/ / n2t.net/addgene:12259; RRID:Addgene_12259, accessed on: 10 December 2021)

To generate cells stably expressing of mRFP-GFP-MAP1LC3B using the plasmid ptfLC3 (addgene \#21074, [53]), pMRX-IP-GFP-LC3-RFP-LC3 $\Delta$ G (addgene \#84572, [54]) or mGALS3-mCherry using pmCherry-Gal3 (addgene \#85662, [63]) the cells were transfected with Lipfectamine 3000 as described above and selected with $1 \mathrm{mg} / \mathrm{mL}$ G418 (geneticin disulphate solution; Carl Roth $\mathrm{GmbH}+\mathrm{Co}$. KG). ptfLC3 was a gift from Tamotsu Yoshimori (Addgene plasmid \#21074; http:/ / n2t.net/addgene:21074; RRID:Addgene_21074, accessed on: 10 December 2021). pMRX-IP-GFP-LC3-RFP-LC3 $\Delta$ G was a gift from Noboru Mizushima (Addgene plasmid \#84572; http:/ / n2t.net/addgene:84572; RRID:Addgene_84572, accessed on: 10 December 2021). pmCherry-Gal3 was a gift from Hemmo Meyer (Addgene plasmid \#85662; http:/ /n2t.net/addgene:85662; RRID:Addgene_85662, accessed on: 10 December 2021).

To re-express STAT3 into MZ-54 STAT3-KO, we used the plasmid pDONR223_STAT3_WT (addgene \#82235; [84]) to clone the STAT3 coding sequence into the plasmid pLenti CMV Puro DEST (w118-1) (addgene \#17452; [85]) using a Gateway LR Clonase Reaction (Thermo Fisher) according to the instructions of the manufacturer. The resulting plasmid pLenti CMV Puro DEST_STAT3_WT was used to generate viral supernatant. pDONR223_STAT3_WT was a gift from Jesse Boehm \& William Hahn \& David Root (Addgene plasmid \#82235; http://n2t.net/addgene:82235; RRID:Addgene_82235, accessed on: 10 December 2021). pLenti CMV Puro DEST (w118-1) was a gift from Eric Campeau \& Paul Kaufman (Addgene plasmid \#17452; http:/ / n2t.net/addgene:17452; RRID:Addgene_17452, accessed on: 10 December 2021). All cell lines were monthly tested for mycoplasma infection using the PCR Mycoplasma Test Kit II (AppliChem) and only negatively tested cells were used for experiments.

\subsection{Compounds, Antibodies and Taqman-Probes}

The following compounds were dissolved in dimethyl-sulfoxide (DMSO; Carl Roth, Karlsruhe, Germany): imipramine hydrochloride (IM; Sigma-Aldrich), ticlopidine hy- 
drochloride (TIC; Sigma-Aldrich), Pimozide (Pimo; Sigma-Aldrich), STF-62247 (STF, Santa Cruz), ABT-737 (ABT, Santa Cruz), Etoposide (Etopo, Enzo Life Sciences, Lörrach, Germany), Fillipin III (Abcam Biochemicals, Cambridge, UK), U18666A (Abcam Biochemicals), Digitonin (Sigma-Aldrich) E64D (Biomol, Hamburg, Germany), Pepstatin A (PepA, Applichem, Darmstadt, Germany).

The following antibodies were used in this study: CTSB (CST, \#31718), 1:1000 (WB), CTSD (CST, \#2284), 1:1000 (WB), GAPDH (Calbiochem, \#CB1001, Darmstadt, Germany) 1:20,000 (WB), MAP1LC3B (Thermo Fisher Scientific, Waltham, MA, USA; \# PA1-16930), 1:1000 (WB), LAMP1 (DSHB, Iowa City, IA, USA, \# H4A3-s), 1:250 (WB), 1:25 (Immunofluorescence (IF)), STAT3 (Cell Signaling Technologies (CST), \#9139), 1:1000 (Western Blot (WB)), STAT3 (phospho Tyr705) (CST \#9131), 1:1000 (WB) Stat3 (Santa Cruz, c-20; sc-482), 1:200 (WB), Tubulin (clone DM1A) (Sigma-Aldrich), 1:10,000 (WB).

The following Taqman-Probes were used in this study: APOL2 (Hs01935263_s1), APOL3 (Hs00600896_m1), APOL6 (Hs00229051_m1), BIN1 (Hs00184913_m1), BNIP3 (Hs00 969291_m1), BNIP3L (Hs00188949_m1), CTSA (Hs00264902_m1), CTSL (Hs00964650_m1), HIF1A (Hs00153153_m1), MMP1 (Hs00899658_m1), MMP2 (Hs01548728_m1), MMP9 (Hs00957555_m1), NPRL3 (Hs00429221_m1), PLAC8 (Hs00930964_g1), SLC2A1 (Hs008926 81_m1), SLC2A3 (Hs00359840_m1), SLC66A1 (Hs01120803_m1), SNAI1 (Hs00195591_m1), TBP (Hs00427620_m1).

\subsection{SDS-PAGE and Western Blot}

Preparation of protein lysates, SDS-PAGE and Western Blotting was performed as described [21]. Briefly, membranes were blocked using 5\% BSA/TBS-Tween20 (TBS-T) or $5 \%$ Milk/TBS-T for $1 \mathrm{~h}$ at room temperature. Primary antibodies were diluted as stated above in 5\% BSA/TBS-T or 5\% Milk/TBS-T at $4{ }^{\circ} \mathrm{C}$ overnight. Secondary goat anti-mouse or goat anti-rabbit (dilution 1:10,000, Li-Cor Biosciences, Bad Homburg, Germany) were incubated at room temperature for $1 \mathrm{~h}$ and detection was achieved using a LI-COR Odyssey reader (LI-COR Biosciences).

Digitonin-based fractionation was performed as described previously $[38,86]$. Briefly, cells were pelleted, resuspended in $50 \mu \mathrm{L}$ PBS (Gibco) and incubated with $50 \mu \mathrm{g} / \mu \mathrm{L}$ digitonin for $15 \mathrm{~min}$ while rotating. The cytosolic fraction was separated from the lysosomal compartment through differential centrifugation.

\subsection{Cell-Based Assays}

MTT (3-(4,5-Dimethylthiazol-2-yl)-2,5-diphenyltetrazolium bromide) assay was basically performed as described previously [87]. Briefly, 2000 to 3000 cells were seeded into 96-well plates and at the indicated time points MTT reagent $(5 \mathrm{mg} / \mathrm{mL}$ in PBS, SigmaAldrich) was added and incubated for $3 \mathrm{~h}$ at $37^{\circ} \mathrm{C}$. After removal of the medium and dissolving of formazon crystals using a mixture of 1M HCL:Isopropanol (ration 1:24 v/v) absorbance was measured using a Tecan Spark plate reader (Tecan, Grödig, Austria).

For Scratch assays 200,000 to 350,000 cells were seeded into 6-well plates. The next day $10 \mu \mathrm{g} / \mu \mathrm{L}$ Mitomycin C (Sigma-Aldrich) was added for $2 \mathrm{~h}$ to inhibit cell division. Hereafter a "scratch" was applied using a pipet tip and after refreshing of the medium (without Mitomycin C) the starting point $(0 \mathrm{~h})$ was captured using a Nikon eclipse TE2000-S inverted fluorescence microscope operated by NIS Elements AR version 3.2 at $4 \times$ magnification. After the indicated incubation times the same regions were examined again and migrating cells were manually counted with the Cell Counter tool from FIJI [88].

Tumor cell invasion was determined using the Cultrex ${ }^{\circledR} 96$ Well 3D Spheroid BME Cell Invasion assay (Trevigen, Gaithersburg, MD, USA) according to the manufacturer's instructions. Therefore, 3000-5000 cells were seeded in U-bottomed 96 well plate in $4{ }^{\circ} \mathrm{C}$ cold $1 \times$ Spheroid Formation Extracellular Matrix (ECM). Samples were centrifuged at $200 \times g$ for $3 \mathrm{~min}$ at RT to center the cells. Afterwards, samples were incubated for $72 \mathrm{~h}$ under culture conditions to allow spheroid formation. Next, the whole plate was chilled for $15 \mathrm{~min}$ on ice. Continuously working on ice, $50 \mu \mathrm{L}$ Invasion Matrix were added to each 
sample followed by centrifugation at $300 \times g$ for $4 \mathrm{~min}$ at $4{ }^{\circ} \mathrm{C}$. To promote formation of the Invasion Matrix gel, samples were incubated for $1 \mathrm{~h}$ at $37^{\circ} \mathrm{C}$ and $5 \% \mathrm{CO}_{2}$. Subsequently, $100 \mu \mathrm{L}$ FBS-containing medium was added. The spheroids were directly analyzed from $0 \mathrm{~h}$ to $48 \mathrm{~h}$ with Eclipse TS100 inverted fluorescence microscope using $4 \times$ magnification and NIS Elements AR software (version 3.22). Quantitation of the area invaded by the tumor cells occurred with Fiji [88]. Therefore, the threshold to discriminate spheroids from background was adjusted manually and the total area was measured (minimum particle size: 50 pixel $^{2}$ ). To exclude area changes due to proliferation or spheroid core shrinkage as it may be the case in highly invasive cells [89], the core size was measured and subtracted from the whole area.

\subsection{Flow Cytometry-Based Assays}

All flow cytometry-based application were measured on a BD FACS Aria II or a BD Accuri C6 (BD Biosciences, Franklin Lakes, NJ, USA), per sample 10,000 cells were analyzed.

Annexin V/Propidium Iodide (PI) assay was performed as described previously [82]. Briefly, cells were trypsinized, pelleted and resuspended in FACS-buffer (10 mM HEPES/NaOH $\mathrm{pH} 7.4,140 \mathrm{mM} \mathrm{NaCl}, 5 \mathrm{mM} \mathrm{CaCl} 2$ ) containing Annexin V-APC (BD Biosciences) or Annexin V-Fluos (BD Biosciences) and PI and measured within $2 \mathrm{~h}$.

EGFP-LC3-mRFP-LC3 $\Delta \mathrm{G}$ [54] fluorescence was measured on a BD Accuri C6 after the cells were harvested and resuspended PBS. The cells were measured in the FL-1 (EGFP) and FL-3 (mRFP) channels of a BD Accuri C6 and the ratio of EGFP/mRFP was calculated to estimate the autophagic flux.

Lysotracker $^{\mathrm{TM}}$ Deep Red (excitation/emission max 647/668 nM; Thermo Fisher) was used according to the manufacturer's instruction. Briefly, $30 \mathrm{~min}$ prior to cell harvesting $25 \mathrm{nM}$ LTDR was added and incubated at $37{ }^{\circ} \mathrm{C}$ in the dark. After trypsination, the cells were pelleted and washed twice with PBS and finally resuspended in $50 \mu \mathrm{L}$ PBS for measurement in the FL-4 channel of a BD Accuri C6.

\subsection{Immunofluorescence Microscopy}

Standard immunofluorescent stainings were performed as described previously [87] using 8-well-chamber slides (Falcon, Corning, Amsterdam, NY, USA) and Alexa Fluor ${ }^{\circledR}$ coupled secondary IgG antibodies (Thermo Fisher).

To monitor the autophagic flux using stable transfectants of ptf-LC3 [53] the cells were treated as indicated and hereafter fixated using $4 \%$ paraformaldehyde (PFA, Santa Cruz) for $20 \mathrm{~min}$ at RT. After three washing steps with cold PBS the slides were briefly rinsed with de-salted $\mathrm{H}_{2} \mathrm{O}$ and mounted DAPI containing immunoselect antifading mounting medium (Dianova, Hamburg, Germany).

Cellular cholesterol was stained using the cell-based cholesterol assay kit (Abcam Biochemicals) including filipin III based on the manufacturer's instructions. Afterwards the slides were prepared for standard immunofluorescent stainng against LAMP1 as described above.

To monitor leaky lysosomes stable transfectants of pmCherry-Gal3, excitation/emission max 586/610 nm were treated as indicated and further processed for standard immunofluorescence staining as described above.

All images were acquired using a Nikon eclipse TE2000-S inverted fluorescence microscope operated by NIS Elements AR version 3.2 (both Nikon, Tokyo, Japan).

\subsection{Whole Transcriptome Analyses}

In total, 50-100 ng of total RNA was fragmented by addition of $5 \times$ fragmentation buffer (200 mM Tris acetate, $\mathrm{pH} 8.2,500 \mathrm{mM}$ potassium acetate and $150 \mathrm{mM}$ magnesium acetate) and heating at $94{ }^{\circ} \mathrm{C}$ for $2 \mathrm{~min}$ in a thermocycler followed by ethanol precipitation with ammonium acetate and GlycoBlue (Life Technologies) as carrier. Fragmented RNA was further processed using the Ovation Human FFPE RNA-Seq Library Systems (Tecan) according to the instructions of the manufacturer. This library preparation includes reverse 
transcription using random priming, second strand synthesis, blunt end repair, adapter ligation with nucleotide analog-marked adaptors, strand selection and insert dependent adapter cleavage (inDA-C) to remove rRNA, globin, and other house-keeping transcripts. Target sequences for inDA-C were derived from human sequences. The barcoded libraries were purified and quantified using the Library Quantification Kit-Illumina/Universal (KAPA Biosystems; Sigma-Aldrich). A pool of up to 10 libraries was used for sequencing at a concentration of $10 \mathrm{nM}$. Sequencing of $2 \times 150 \mathrm{bp}$ was performed with an Illumina NextSeq 550 sequencer at the sequencing core facility of the IZKF Leipzig (Faculty of Medicine, University Leipzig) according to the instructions of the manufacturer. Demultiplexing of raw reads, adapter trimming and quality filtering was done according to Stokowy et al. [90]. Mapping of the remaining reads against the human reference genome (hg38) was done using TopHat 2 and Cufflinks 2 [91,92].

To analyze biologically relevant signaling pathways we employed the PANTHERtool (http:/ / www.pantherdb.org/; v14.1, accessed on: 7 May 2019) [56,93] to perform an enrichment analysis. For this purpose all gene names together with their log2 fold-change in gene expression after STAT3-KO were imported to PANTHER and significantly enriched pathways were selected.

\subsection{Taqman-Based Gene Expression Analyses}

RNA-isolation and cDNA-synthesis was performed as described previously [87]. Briefly, RNA-Isolation was performed using the ExtractMe Total RNA Kit (Blirt S.A., Gdansk, Poland) and cDNA-synthesis was achieved using the SuperScript III System (Life Technologies, Darmstadt, Germany) according to the manufacturers instruction using $100 \mathrm{U}$ SuperScript per sample. The quantitative Real-Time PCR (qRT-PCR) was performed using $2 \times$ Fast-Start Universal Probe Master Mix (Roche, Risch, Switzerland) and 20× Taqman Probes (Applied Biosystems, Darmstadt, Germany) on a StepOne Plus System (Applied Biosystems) using the standard setting. The target gene expression values were normalized to the reference gene TATA-box binding protein (TBP).

\section{Conclusions}

Here, we present a novel pro-death function of the oncoprotein STAT3, which is frequently overactivated in multiple human cancers including glioblastoma and is associated with the most aggressive mesenchymal subtype. Using isogenic Crispr/Cas9-Knockouts and stable shRNA-mediated STAT3-KD cells we show that loss of STAT3 leads to reduced sensitivity to known ACD-inducers. We show further that this is accompanied by reduced lysosomal lipid accumulation in STAT3-deficient cells and therefore less leakage of lysosomal contents in the cytosol, which causes LDCD in STAT3-proficient cells. In conclusion, these findings offer new research directions to develop targeted therapies of STAT3-activated, autophagy-proficient tumors such as glioblastoma.

Supplementary Materials: The following are available online at https: / www.mdpi.com/article / 10.3390/cancers14020339/s1, Figure S1. STAT3 expression and activation across 12 GBM cultures. Figure S2: Functional Validation of Crispr/Cas9-mediated STAT3-Knockouts. Figure S3. Stable shRNA-mediated depletion of STAT3 protects GBM cells from autophagy-dependent cell death. Figure S4. Stable overexpression of STAT3in STAT3-deficient cells restores sensitivity to Pimozideinduced cell death. Figure S5. Mesenchymal glioblastoma stem-like cells are more sensitive to Pimozide-treatment compared to proneural GSCs. Figure S6. Depletion of STAT3 does not change autophagic flux at the level of autophagosome-lysosome-fusion. Figure S7. Transcriptomic analyses after STAT3 depletion in MZ-54-cells reveal changes in lipid metabolism and validation of selected target genes using STAT3-KD cells. Figure S8. Correlation of STAT3 with selected candidate genes from TCGA data. Figure S9. Depletion of STAT3 reduces lysosomal cholesterol-accumulation and lysosomal acidification. Table S1: Correlation of STAT3 expression and selected candidate genes from TCGA data. Supplementary File: Original Blots. 


\begin{abstract}
Author Contributions: Conceptualization, J.R., B.L., U.W., A.A. and D.K.; Data curation, J.R., B.L. and K.K.; Formal analysis, B.L. and K.K.; Funding acquisition, A.A. and D.K.; Investigation, J.R. and B.L.; Methodology, J.R. and B.L.; Project administration, D.K.; Resources, B.W.D., B.W.S., C.H.-M., K.K. and D.K.; Supervision, B.L. and D.K.; Validation, B.L.; Visualization, J.R. and B.L.; Writing-original draft, J.R., B.L. and D.K.; Writing-review and editing, B.L., U.W., B.W.D., B.W.S., C.H.-M., A.A., K.K. and D.K. All authors have read and agreed to the published version of the manuscript.
\end{abstract}

Funding: This study was supported by the German Research Foundation (Deutsche Forschungsgemeinschaft)—Project-ID 259130777_SFB 1177 E09 to D.K.; KO 1898 9/1 to D.K.; AI 24/13-1 to AA.

Institutional Review Board Statement: Not applicable.

Informed Consent Statement: Not applicable.

Data Availability Statement: Deep sequencing datasets generated and analysed during the current study are available in the Gene Expression Omnibus (GEO) repository, accession number GSE162429.

Acknowledgments: We thank Hildegard König for excellent technical assistance. Symbols for the Graphical Abstract were taken from Smart Servier Medical Art. Permission for reproduction of the symbols: Creative Commons Attribution 3.0 Unported (CC BY 3.0), https:/ / smart.servier.com; accessed on: 10 April 2018).

Conflicts of Interest: The authors declare no conflict of interest. The funders had no role in the design of the study; in the collection, analyses, or interpretation of data; in the writing of the manuscript, or in the decision to publish the results.

\title{
References
}

1. Louis, D.N.; Perry, A.; Reifenberger, G.; von Deimling, A.; Figarella-Branger, D.; Cavenee, W.K.; Ohgaki, H.; Wiestler, O.D.; Kleihues, P.; Ellison, D.W. The 2016 World Health Organization classification of tumors of the central nervous system: A summary. Acta Neuropathol. 2016, 131, 803-820. [CrossRef] [PubMed]

2. Becker, K.P.; Yu, J. Status quo-standard-of-care medical and radiation therapy for glioblastoma. Cancer J. 2012, 18, 12-19. [CrossRef] [PubMed]

3. Verhaak, R.G.; Hoadley, K.A.; Purdom, E.; Wang, V.; Qi, Y.; Wilkerson, M.D.; Miller, C.R.; Ding, L.; Golub, T.; Mesirov, J.P.; et al. Integrated genomic analysis identifies clinically relevant subtypes of glioblastoma characterized by abnormalities in PDGFRA, IDH1, EGFR, and NF1. Cancer Cell 2010, 17, 98-110. [CrossRef]

4. Olar, A.; Aldape, K.D. Using the molecular classification of glioblastoma to inform personalized treatment. J. Pathol. 2014, 232, 165-177. [CrossRef] [PubMed]

5. Carro, M.S.; Lim, W.K.; Alvarez, M.J.; Bollo, R.J.; Zhao, X.; Snyder, E.Y.; Sulman, E.P.; Anne, S.L.; Doetsch, F.; Colman, H.; et al. The transcriptional network for mesenchymal transformation of brain tumours. Nature 2010, 463, 318-325. [CrossRef]

6. Hossain, A.; Gumin, J.; Gao, F.; Figueroa, J.; Shinojima, N.; Takezaki, T.; Priebe, W.; Villarreal, D.; Kang, S.G.; Joyce, C.; et al. Mesenchymal stem cells isolated from human gliomas increase proliferation and maintain stemness of glioma stem cells through the IL-6/gp130/STAT3 pathway. Stem Cells 2015, 33, 2400-2415. [CrossRef]

7. Yu, H.; Lee, H.; Herrmann, A.; Buettner, R.; Jove, R. Revisiting STAT3 signalling in cancer: New and unexpected biological functions. Nat. Rev. Cancer 2014, 14, 736-746. [CrossRef]

8. Galoczova, M.; Coates, P.; Vojtesek, B. STAT3, stem cells, cancer stem cells and p63. Cell. Mol. Biol. Lett. 2018, 23, 12. [CrossRef]

9. Kim, J.E.; Patel, M.; Ruzevick, J.; Jackson, C.M.; Lim, M. STAT3 Activation in glioblastoma: Biochemical and therapeutic implications. Cancers 2014, 6, 376-395. [CrossRef]

10. Brantley, E.C.; Benveniste, E.N. Signal transducer and activator of transcription-3: A molecular hub for signaling pathways in gliomas. Mol. Cancer Res. 2008, 6, 675-684. [CrossRef]

11. Luwor, R.B.; Baradaran, B.; Taylor, L.E.; Iaria, J.; Nheu, T.V.; Amiry, N.; Hovens, C.M.; Wang, B.; Kaye, A.H.; Zhu, H.J. Targeting Stat3 and Smad7 to restore TGF-beta cytostatic regulation of tumor cells in vitro and in vivo. Oncogene 2013, 32, $2433-2441$. [CrossRef] [PubMed]

12. Westermarck, J.; Kahari, V.M. Regulation of matrix metalloproteinase expression in tumor invasion. FASEB J. 1999, 13, 781-792. [CrossRef] [PubMed]

13. Wendt, M.K.; Balanis, N.; Carlin, C.R.; Schiemann, W.P. STAT3 and epithelial-mesenchymal transitions in carcinomas. JAK-STAT 2014, 3, e28975. [CrossRef]

14. Kudo-Saito, C.; Shirako, H.; Takeuchi, T.; Kawakami, Y. Cancer metastasis is accelerated through immunosuppression during Snail-induced EMT of cancer cells. Cancer Cell 2009, 15, 195-206. [CrossRef]

15. Esposito, C.L.; Nuzzo, S.; Catuogno, S.; Romano, S.; de Nigris, F.; de Franciscis, V. STAT3 gene silencing by aptamer-siRNA chimera as selective therapeutic for glioblastoma. Mol. Ther. Nucleic Acids 2018, 10, 398-411. [CrossRef] [PubMed] 
16. Kiprianova, I.; Remy, J.; Milosch, N.; Mohrenz, I.V.; Seifert, V.; Aigner, A.; Kogel, D. Sorafenib sensitizes glioma cells to the BH3 mimetic ABT-737 by targeting MCL1 in a STAT3-dependent manner. Neoplasia 2015, 17, 564-573. [CrossRef] [PubMed]

17. Priester, M.; Copanaki, E.; Vafaizadeh, V.; Hensel, S.; Bernreuther, C.; Glatzel, M.; Seifert, V.; Groner, B.; Kogel, D.; Weissenberger J. STAT3 silencing inhibits glioma single cell infiltration and tumor growth. Neuro-Oncology 2013, 15, 840-852. [CrossRef]

18. Senft, C.; Priester, M.; Polacin, M.; Schroder, K.; Seifert, V.; Kogel, D.; Weissenberger, J. Inhibition of the JAK-2/STAT3 signaling pathway impedes the migratory and invasive potential of human glioblastoma cells. J. Neuro-Oncol. 2011, 101, 393-403. [CrossRef]

19. Sherry, M.M.; Reeves, A.; Wu, J.L.K.; Cochran, B.H. STAT3 is required for proliferation and maintenance of multipotency in glioblastoma stem cells. Stem Cells 2009, 27, 2383-2392. [CrossRef]

20. Takeda, K.; Kaisho, T.; Yoshida, N.; Takeda, J.; Kishimoto, T.; Akira, S. Stat3 activation is responsible for IL-6-dependent T cell proliferation through preventing apoptosis: Generation and characterization of T cell-specific Stat3-deficient mice. J. Immunol. 1998, 161, 4652-4660. [CrossRef]

21. Linder, B.; Weirauch, U.; Ewe, A.; Uhmann, A.; Seifert, V.; Mittelbronn, M.; Harter, P.N.; Aigner, A.; Kogel, D. Therapeutic targeting of Stat 3 using lipopolyplex nanoparticle-formulated siRNA in a syngeneic orthotopic mouse glioma model. Cancers 2019, 11, 333. [CrossRef] [PubMed]

22. Gong, J.; Munoz, A.R.; Chan, D.; Ghosh, R.; Kumar, A.P. STAT3 down regulates LC3 to inhibit autophagy and pancreatic cancer cell growth. Oncotarget 2014, 5, 2529-2541. [CrossRef] [PubMed]

23. Sun, L.; Hu, L.; Cogdell, D.; Lu, L.; Gao, C.; Tian, W.; Zhang, Z.; Kang, Y.; Fleming, J.B.; Zhang, W. MIR506 induces autophagyrelated cell death in pancreatic cancer cells by targeting the STAT3 pathway. Autophagy 2017, 13, 703-714. [CrossRef]

24. Jung, J.E.; Lee, H.G.; Cho, I.H.; Chung, D.H.; Yoon, S.H.; Yang, Y.M.; Lee, J.W.; Choi, S.; Park, J.W.; Ye, S.K.; et al. STAT3 is a potential modulator of HIF-1-mediated VEGF expression in human renal carcinoma cells. FASEB J. 2005, 19, 1296-1298. [CrossRef] [PubMed]

25. Jung, J.E.; Kim, H.S.; Lee, C.S.; Shin, Y.J.; Kim, Y.N.; Kang, G.H.; Kim, T.Y.; Juhnn, Y.S.; Kim, S.J.; Park, J.W.; et al. STAT3 inhibits the degradation of HIF-1alpha by pVHL-mediated ubiquitination. Exp. Mol. Med. 2008, 40, 479-485. [CrossRef]

26. Pratt, J.; Annabi, B. Induction of autophagy biomarker BNIP3 requires a JAK2/STAT3 and MT1-MMP signaling interplay in Concanavalin-A-activated U87 glioblastoma cells. Cell. Signal. 2014, 26, 917-924. [CrossRef]

27. Pensa, S.; Lloyd-Lewis, B.; Sargeant, T.J.; Resemann, H.K.; Kahn, C.R.; Watson, C.J. Signal transducer and activator of transcription 3 and the phosphatidylinositol 3-kinase regulatory subunits p55alpha and p50alpha regulate autophagy in vivo. FEBS J. 2014, 281, 4557-4567. [CrossRef]

28. Shen, S.; Niso-Santano, M.; Adjemian, S.; Takehara, T.; Malik, S.A.; Minoux, H.; Souquere, S.; Marino, G.; Lachkar, S.; Senovilla, L.; et al. Cytoplasmic STAT3 represses autophagy by inhibiting PKR activity. Mol. Cell 2012, 48, 667-680. [CrossRef]

29. Szczepanek, K.; Chen, Q.; Larner, A.C.; Lesnefsky, E.J. Cytoprotection by the modulation of mitochondrial electron transport chain: The emerging role of mitochondrial STAT3. Mitochondrion 2012, 12, 180-189. [CrossRef]

30. Szczepanek, K.; Lesnefsky, E.J.; Larner, A.C. Multi-tasking: Nuclear transcription factors with novel roles in the mitochondria. Trends Cell Biol. 2012, 22, 429-437. [CrossRef] [PubMed]

31. Wegrzyn, J.; Potla, R.; Chwae, Y.J.; Sepuri, N.B.; Zhang, Q.; Koeck, T.; Derecka, M.; Szczepanek, K.; Szelag, M.; Gornicka, A.; et al Function of mitochondrial Stat3 in cellular respiration. Science 2009, 323, 793-797. [CrossRef]

32. You, L.; Wang, Z.; Li, H.; Shou, J.; Jing, Z.; Xie, J.; Sui, X.; Pan, H.; Han, W. The role of STAT3 in autophagy. Autophagy 2015, 11, 729-739. [CrossRef]

33. Sargeant, T.J.; Lloyd-Lewis, B.; Resemann, H.K.; Ramos-Montoya, A.; Skepper, J.; Watson, C.J. Stat3 controls cell death during mammary gland involution by regulating uptake of milk fat globules and lysosomal membrane permeabilization. Nat. Cell Biol. 2014, 16, 1057-1068. [CrossRef] [PubMed]

34. Kreuzaler, P.A.; Staniszewska, A.D.; Li, W.; Omidvar, N.; Kedjouar, B.; Turkson, J.; Poli, V.; Flavell, R.A.; Clarkson, R.W.; Watson, C.J. Stat3 controls lysosomal-mediated cell death in vivo. Nat. Cell Biol. 2011, 13, 303-309. [CrossRef] [PubMed]

35. Li, L.; Sun, B.; Gao, Y.; Niu, H.; Yuan, H.; Lou, H. STAT3 contributes to lysosomal-mediated cell death in a novel derivative of riccardin D-treated breast cancer cells in association with TFEB. Biochem. Pharmacol. 2018, 150, 267-279. [CrossRef]

36. de Duve, C. Lysosomes revisited. Eur. J. Biochem. 1983, 137, 391-397. [CrossRef]

37. Serrano-Puebla, A.; Boya, P. Lysosomal membrane permeabilization in cell death: New evidence and implications for health and disease. Ann. N. Y. Acad. Sci. 2016, 1371, 30-44. [CrossRef] [PubMed]

38. Meyer, N.; Henkel, L.; Linder, B.; Zielke, S.; Tascher, G.; Trautmann, S.; Geisslinger, G.; Münch, C.; Fulda, S.; Tegeder, I.; et al. Autophagy activation, lipotoxicity and lysosomal membrane permeabilization synergize to promote pimozide- and loperamide-induced glioma cell death. Autophagy 2020, 17, 3424-3443. [CrossRef] [PubMed]

39. Aits, S.; Jaattela, M. Lysosomal cell death at a glance. J. Cell Sci. 2013, 126, 1905-1912. [CrossRef]

40. Gomez-Sintes, R.; Ledesma, M.D.; Boya, P. Lysosomal cell death mechanisms in aging. Ageing Res. Rev. 2016, 32, 150-168. [CrossRef] [PubMed]

41. Stoka, V.; Turk, V.; Turk, B. Lysosomal cathepsins and their regulation in aging and neurodegeneration. Ageing Res. Rev. 2016, 32, 22-37. [CrossRef] [PubMed]

42. Kallunki, T.; Olsen, O.D.; Jaattela, M. Cancer-associated lysosomal changes: Friends or foes? Oncogene 2013, 32, 1995-2004. [CrossRef] [PubMed]

43. Piao, S.; Amaravadi, R.K. Targeting the lysosome in cancer. Ann. N. Y. Acad. Sci. 2016, 1371, 45-54. [CrossRef] 
44. Galluzzi, L.; Vitale, I.; Aaronson, S.A.; Abrams, J.M.; Adam, D.; Agostinis, P.; Alnemri, E.S.; Altucci, L.; Amelio, I.; Andrews, D.W.; et al. Molecular mechanisms of cell death: Recommendations of the Nomenclature Committee on Cell Death 2018. Cell Death Differ. 2018, 25, 486-541. [CrossRef]

45. Senft, C.; Polacin, M.; Priester, M.; Seifert, V.; Kogel, D.; Weissenberger, J. The nontoxic natural compound Curcumin exerts anti-proliferative, anti-migratory, and anti-invasive properties against malignant gliomas. BMC Cancer 2010, 10, 491. [CrossRef]

46. Li, R.; Li, G.; Deng, L.; Liu, Q.; Dai, J.; Shen, J.; Zhang, J. IL-6 augments the invasiveness of U87MG human glioblastoma multiforme cells via up-regulation of MMP-2 and fascin-1. Oncol. Rep. 2010, 23, 1553-1559. [CrossRef]

47. Demaria, M.; Giorgi, C.; Lebiedzinska, M.; Esposito, G.; D’Angeli, L.; Bartoli, A.; Gough, D.J.; Turkson, J.; Levy, D.E.; Watson, C.J.; et al. A STAT3-mediated metabolic switch is involved in tumour transformation and STAT3 addiction. Aging 2010, 2, 823-842. [CrossRef]

48. Shchors, K.; Massaras, A.; Hanahan, D. Dual targeting of the autophagic regulatory circuitry in gliomas with repurposed drugs elicits cell-lethal autophagy and therapeutic benefit. Cancer Cell 2015, 28, 456-471. [CrossRef]

49. Zielke, S.; Meyer, N.; Mari, M.; Abou-El-Ardat, K.; Reggiori, F.; van Wijk, S.J.L.; Kogel, D.; Fulda, S. Loperamide, pimozide, and STF-62247 trigger autophagy-dependent cell death in glioblastoma cells. Cell Death Dis. 2018, 9, 994. [CrossRef] [PubMed]

50. Stringer, B.W.; Day, B.W.; D'Souza, R.C.J.; Jamieson, P.R.; Ensbey, K.S.; Bruce, Z.C.; Lim, Y.C.; Goasdoue, K.; Offenhauser, C.; Akgul, S.; et al. A reference collection of patient-derived cell line and xenograft models of proneural, classical and mesenchymal glioblastoma. Sci. Rep. 2019, 9, 4902. [CrossRef]

51. Campos, B.; Gal, Z.; Baader, A.; Schneider, T.; Sliwinski, C.; Gassel, K.; Bageritz, J.; Grabe, N.; von Deimling, A.; Beckhove, P.; et al. Aberrant self-renewal and quiescence contribute to the aggressiveness of glioblastoma. J. Pathol. 2014, 234, 23-33. [CrossRef] [PubMed]

52. Campos, B.; Wan, F.; Farhadi, M.; Ernst, A.; Zeppernick, F.; Tagscherer, K.E.; Ahmadi, R.; Lohr, J.; Dictus, C.; Gdynia, G.; et al. Differentiation therapy exerts antitumor effects on stem-like glioma cells. Clin. Cancer Res. 2010, 16, 2715-2728. [CrossRef] [PubMed]

53. Kimura, S.; Noda, T.; Yoshimori, T. Dissection of the autophagosome maturation process by a novel reporter protein, tandem fluorescent-tagged LC3. Autophagy 2007, 3, 452-460. [CrossRef] [PubMed]

54. Kaizuka, T.; Morishita, H.; Hama, Y.; Tsukamoto, S.; Matsui, T.; Toyota, Y.; Kodama, A.; Ishihara, T.; Mizushima, T.; Mizushima, N. An autophagic flux probe that releases an internal control. Mol. Cell 2016, 64, 835-849. [CrossRef]

55. Duchateau, P.N.; Pullinger, C.R.; Orellana, R.E.; Kunitake, S.T.; Naya-Vigne, J.; O'Connor, P.M.; Malloy, M.J.; Kane, J.P. Apolipoprotein L, a new human high density lipoprotein apolipoprotein expressed by the pancreas: Identification, cloning, characterization, and plasma distribution of apolipoprotein L. J. Biol. Chem. 1997, 272, 25576-25582. [CrossRef]

56. Mi, H.; Muruganujan, A.; Ebert, D.; Huang, X.; Thomas, P.D. PANTHER version 14: More genomes, a new PANTHER GO-slim and improvements in enrichment analysis tools. Nucleic Acids Res. 2019, 47, D419-D426. [CrossRef]

57. Meyer, N.; Zielke, S.; Michaelis, J.B.; Linder, B.; Warnsmann, V.; Rakel, S.; Osiewacz, H.D.; Fulda, S.; Mittelbronn, M.; Munch, C.; et al. AT 101 induces early mitochondrial dysfunction and HMOX1 (heme oxygenase 1) to trigger mitophagic cell death in glioma cells. Autophagy 2018, 14, 1693-1709. [CrossRef]

58. Pan, K.; Liang, X.T.; Zhang, H.K.; Zhao, J.J.; Wang, D.D.; Li, J.J.; Lian, Q.; Chang, A.E.; Li, Q.; Xia, J.C. Characterization of bridging integrator 1 (BIN1) as a potential tumor suppressor and prognostic marker in hepatocellular carcinoma. Mol. Med. 2012, 18, 507-518. [CrossRef]

59. Kinsey, C.; Balakrishnan, V.; O’Dell, M.R.; Huang, J.L.; Newman, L.; Whitney-Miller, C.L.; Hezel, A.F.; Land, H. Plac8 links oncogenic mutations to regulation of autophagy and is critical to pancreatic cancer progression. Cell Rep. 2014, 7, $1143-1155$. [CrossRef]

60. Bowman, R.L.; Wang, Q.; Carro, A.; Verhaak, R.G.; Squatrito, M. GlioVis data portal for visualization and analysis of brain tumor expression datasets. Neuro-Oncology 2017, 19, 139-141. [CrossRef] [PubMed]

61. The Cancer Genome Atlas Research Network. Comprehensive genomic characterization defines human glioblastoma genes and core pathways. Nature 2008, 455, 1061-1068. [CrossRef]

62. Kristiana, I.; Sharpe, L.J.; Catts, V.S.; Lutze-Mann, L.H.; Brown, A.J. Antipsychotic drugs upregulate lipogenic gene expression by disrupting intracellular trafficking of lipoprotein-derived cholesterol. Pharmacogenomics J. 2010, 10, 396-407. [CrossRef] [PubMed]

63. Papadopoulos, C.; Kirchner, P.; Bug, M.; Grum, D.; Koerver, L.; Schulze, N.; Poehler, R.; Dressler, A.; Fengler, S.; Arhzaouy, K.; et al. VCP/p97 cooperates with YOD1, UBXD1 and PLAA to drive clearance of ruptured lysosomes by autophagy. EMBO J. 2017, 36, 135-150. [CrossRef] [PubMed]

64. Aits, S.; Kricker, J.; Liu, B.; Ellegaard, A.M.; Hamalisto, S.; Tvingsholm, S.; Corcelle-Termeau, E.; Hogh, S.; Farkas, T.; Jonassen, A.H.; et al. Sensitive detection of lysosomal membrane permeabilization by lysosomal galectin puncta assay. Autophagy 2015, 11, 1408-1424. [CrossRef] [PubMed]

65. Levy, D.E.; Lee, C.K. What does Stat3 do? J. Clin. Investig. 2002, 109, 1143-1148. [CrossRef]

66. Liu, Y.; Li, C.; Lin, J. STAT3 as a therapeutic target for glioblastoma. Anti-Cancer Agents Med. Chem. 2010, 10, 512-519. [CrossRef]

67. Shi, Y.; Guryanova, O.A.; Zhou, W.; Liu, C.; Huang, Z.; Fang, X.; Wang, X.; Chen, C.; Wu, Q.; He, Z.; et al. Ibrutinib inactivates BMX-STAT3 in glioma stem cells to impair malignant growth and radioresistance. Sci. Transl. Med. 2018, 10, 600. [CrossRef]

68. Voss, V.; Senft, C.; Lang, V.; Ronellenfitsch, M.W.; Steinbach, J.P.; Seifert, V.; Kogel, D. The pan-Bcl-2 inhibitor (-)-gossypol triggers autophagic cell death in malignant glioma. Mol. Cancer Res. 2010, 8, 1002-1016. [CrossRef] 
69. Hernandez-Tiedra, S.; Fabrias, G.; Davila, D.; Salanueva, I.J.; Casas, J.; Montes, L.R.; Anton, Z.; Garcia-Taboada, E.; Salazar-Roa, M.; Lorente, M.; et al. Dihydroceramide accumulation mediates cytotoxic autophagy of cancer cells via autolysosome destabilization. Autophagy 2016, 12, 2213-2229. [CrossRef]

70. Salazar, M.; Carracedo, A.; Salanueva, I.J.; Hernandez-Tiedra, S.; Lorente, M.; Egia, A.; Vazquez, P.; Blazquez, C.; Torres, S.; Garcia, S.; et al. Cannabinoid action induces autophagy-mediated cell death through stimulation of ER stress in human glioma cells. J. Clin. Invest. 2009, 119, 1359-1372. [CrossRef]

71. Kornhuber, J.; Tripal, P.; Reichel, M.; Muhle, C.; Rhein, C.; Muehlbacher, M.; Groemer, T.W.; Gulbins, E. Functional inhibitors of acid sphingomyelinase (FIASMAs): A novel pharmacological group of drugs with broad clinical applications. Cell. Physiol. Biochem. 2010, 26, 9-20. [CrossRef]

72. Petersen, N.H.; Olsen, O.D.; Groth-Pedersen, L.; Ellegaard, A.M.; Bilgin, M.; Redmer, S.; Ostenfeld, M.S.; Ulanet, D.; Dovmark, T.H.; Lønborg, A.; et al. Transformation-associated changes in sphingolipid metabolism sensitize cells to lysosomal cell death induced by inhibitors of acid sphingomyelinase. Cancer Cell 2013, 24, 379-393. [CrossRef] [PubMed]

73. Boya, P.; Kroemer, G. Lysosomal membrane permeabilization in cell death. Oncogene 2008, 27, 6434-6451. [CrossRef] [PubMed]

74. Gabande-Rodriguez, E.; Boya, P.; Labrador, V.; Dotti, C.G.; Ledesma, M.D. High sphingomyelin levels induce lysosomal damage and autophagy dysfunction in Niemann Pick disease type A. Cell Death Differ. 2014, 21, 864-875. [CrossRef]

75. Groth-Pedersen, L.; Jäättelä, M. Combating apoptosis and multidrug resistant cancers by targeting lysosomes. Cancer Lett. 2013, 332, 265-274. [CrossRef]

76. Liu, B.; Palmfeldt, J.; Lin, L.; Colaco, A.; Clemmensen, K.K.B.; Huang, J.; Xu, F.; Liu, X.; Maeda, K.; Luo, Y.; et al. STAT3 associates with vacuolar $\mathrm{H}(+)$-ATPase and regulates cytosolic and lysosomal pH. Cell Res. 2018, 28, 996-1012. [CrossRef]

77. Wiklund, E.D.; Catts, V.S.; Catts, S.V.; Ng, T.F.; Whitaker, N.J.; Brown, A.J.; Lutze-Mann, L.H. Cytotoxic effects of antipsychotic drugs implicate cholesterol homeostasis as a novel chemotherapeutic target. Int. J. Cancer 2010, 126, 28-40. [CrossRef] [PubMed]

78. Kuzu, O.F.; Gowda, R.; Noory, M.A.; Robertson, G.P. Modulating cancer cell survival by targeting intracellular cholesterol transport. Br. J. Cancer 2017, 117, 513-524. [CrossRef]

79. Villa, G.R.; Hulce, J.J.; Zanca, C.; Bi, J.; Ikegami, S.; Cahill, G.L.; Gu, Y.; Lum, K.M.; Masui, K.; Yang, H.; et al. An LXR-cholesterol axis creates a metabolic co-dependency for brain cancers. Cancer Cell 2016, 30, 683-693. [CrossRef] [PubMed]

80. Hetschko, H.; Voss, V.; Horn, S.; Seifert, V.; Prehn, J.H.; Kogel, D. Pharmacological inhibition of Bcl-2 family members reactivates TRAIL-induced apoptosis in malignant glioma. J. Neuro-Oncol. 2008, 86, 265-272. [CrossRef]

81. Smilowitz, H.M.; Weissenberger, J.; Weis, J.; Brown, J.D.; O’Neill, R.J.; Laissue, J.A. Orthotopic transplantation of v-src-expressing glioma cell lines into immunocompetent mice: Establishment of a new transplantable in vivo model for malignant glioma. $J$. Neurosurg. 2007, 106, 652-659. [CrossRef]

82. Remy, J.; Linder, B.; Weirauch, U.; Konovalova, J.; Marschalek, R.; Aigner, A.; Kogel, D. Inhibition of PIM1 blocks the autophagic flux to sensitize glioblastoma cells to ABT-737-induced apoptosis. Biochim. Biophys. Acta (BBA)-Mol. Cell Res. 2019, 1866, 175-189. [CrossRef]

83. Ran, F.A.; Hsu, P.D.; Lin, C.Y.; Gootenberg, J.S.; Konermann, S.; Trevino, A.E.; Scott, D.A.; Inoue, A.; Matoba, S.; Zhang, Y.; et al. Double nicking by RNA-guided CRISPR Cas9 for enhanced genome editing specificity. Cell 2013, 154, 1380-1389. [CrossRef]

84. Kim, E.; Ilic, N.; Shrestha, Y.; Zou, L.; Kamburov, A.; Zhu, C.; Yang, X.; Lubonja, R.; Tran, N.; Nguyen, C.; et al. Systematic functional interrogation of rare cancer variants identifies oncogenic alleles. Cancer Discov. 2016, 6, 714-726. [CrossRef] [PubMed]

85. Campeau, E.; Ruhl, V.E.; Rodier, F.; Smith, C.L.; Rahmberg, B.L.; Fuss, J.O.; Campisi, J.; Yaswen, P.; Cooper, P.K.; Kaufman, P.D. A versatile viral system for expression and depletion of proteins in mammalian cells. PLoS ONE 2009, 4, e6529. [CrossRef] [PubMed]

86. Adrain, C.; Creagh, E.M.; Martin, S.J. Apoptosis-associated release of Smac/DIABLO from mitochondria requires active caspases and is blocked by Bcl-2. EMBO J. 2001, 20, 6627-6636. [CrossRef]

87. Linder, B.; Wehle, A.; Hehlgans, S.; Bonn, F.; Dikic, I.; Rodel, F.; Seifert, V.; Kogel, D. Arsenic trioxide and (-)-gossypol synergistically target glioma stem-like cells via inhibition of hedgehog and notch signaling. Cancers 2019, 11, 350. [CrossRef] [PubMed]

88. Schindelin, J.; Arganda-Carreras, I.; Frise, E.; Kaynig, V.; Longair, M.; Pietzsch, T.; Preibisch, S.; Rueden, C.; Saalfeld, S.; Schmid, B.; et al. Fiji: An open-source platform for biological-image analysis. Nat. Methods 2012, 9, 676-682. [CrossRef] [PubMed]

89. Vinci, M.; Box, C.; Eccles, S.A. Three-dimensional (3D) tumor spheroid invasion assay. J. Vis. Exp. 2015, 99. [CrossRef]

90. Stokowy, T.; Eszlinger, M.; Swierniak, M.; Fujarewicz, K.; Jarzab, B.; Paschke, R.; Krohn, K. Analysis options for high-throughput sequencing in miRNA expression profiling. BMC Res. Notes 2014, 7, 144. [CrossRef]

91. Kim, D.; Pertea, G.; Trapnell, C.; Pimentel, H.; Kelley, R.; Salzberg, S.L. TopHat2: Accurate alignment of transcriptomes in the presence of insertions, deletions and gene fusions. Genome Biol. 2013, 14, R36. [CrossRef] [PubMed]

92. Trapnell, C.; Hendrickson, D.G.; Sauvageau, M.; Goff, L.; Rinn, J.L.; Pachter, L. Differential analysis of gene regulation at transcript resolution with RNA-seq. Nat. Biotechnol. 2013, 31, 46-53. [CrossRef] [PubMed]

93. Mi, H.; Muruganujan, A.; Huang, X.; Ebert, D.; Mills, C.; Guo, X.; Thomas, P.D. Protocol Update for large-scale genome and gene function analysis with the PANTHER classification system (v.14.0). Nat. Protoc. 2019, 14, 703-721. [CrossRef] [PubMed] 